\title{
Formal Inferring the Law of Conservation of Energy from Assuming A-Priori-ness of Knowledge in a Formal Axiomatic Epistemology System Sigma
}

\author{
Vladimir O. Lobovikov \\ Laboratory for Applied System Investigations, Ural Federal University, Yekaterinburg, Russian Federation \\ Email: vlobovikov@mail.ru
}

How to cite this paper: Lobovikov, V.O. (2021) Formal Inferring the Law of Conservation of Energy from Assuming A-Priori-ness of Knowledge in a Formal Axiomatic Epistemology System Sigma. Journal of Applied Mathematics and Physics, 9, 1011-1040. https://doi.org/10.4236/jamp.2021.95070

Received: April 9, 2021

Accepted: May 23, 2021

Published: May 26, 2021

Copyright ( 2021 by author(s) and Scientific Research Publishing Inc. This work is licensed under the Creative Commons Attribution International License (CC BY 4.0).

http://creativecommons.org/licenses/by/4.0/ (c) (i) Open Access

\begin{abstract}
The research purpose is invention (construction) of a formal logical inference of the Law of Conservation of Energy within a logically formalized axiomatic epistemology-and-axiology theory Sigma from a precisely defined assumption of a-priori-ness of knowledge. For realizing this aim, the following work has been done: 1) a two-valued algebraic system of formal axiology has been defined precisely and applied to proper-philosophy of physics, namely, to an almost unknown (not-recognized) formal-axiological aspect of the physical law of conservation of energy; 2) the formal axiomatic epistemology-andaxiology theory Sigma has been defined precisely and applied to properphysics for realizing the above-indicated purpose. Thus, a discrete mathematical model of relationship between philosophy of physics and universal epistemology united with formal axiology has been constructed. Results: 1) By accurate computing relevant compositions of evaluation-functions within the discrete mathematical model, it is demonstrated that a formal-axiological ana$\log$ of the great conservation law of proper physics is a formal-axiological law of two-valued algebra of metaphysics. (A precise algorithmic definition of the unhabitual (not-well-known) notion "formal-axiological law of algebra of metaphysics" is given.) 2) The hitherto never published significantly new nontrivial scientific result of investigation presented in this article is a formal logical inference of the law of conservation of energy within the formal axiomatic theory Sigma from conjunction of the formal-axiological analog of the law of conservation of energy and the assumption of a-priori-ness of knowledge.
\end{abstract}

\section{Keywords}

Law of Conservation of Energy, law of Two Valued Algebra of Formal 
Axiology, Formal Axiomatic Epistemology System Sigma, Apriori

Knowledge, Formal Deductive Inference

\section{Introduction}

The background of research presented in this paper has a long inner history [1]-[8]. Arguments pro-et-contra the idea of perpetuum mobile can be found even in Ancient Greece, for example, in "Physics" and "Metaphysics" by Aristotle [9]. Some of the ancient arguments, substantiating the existence of perpetual movers, were metaphysical, axiological, and even theological ones; gods were considered as perpetual movers very often. If theology is a special aspect of metaphysics, and metaphysics in its essence is nothing but abstract axiology (such understanding subject-matter of metaphysics is manifestly formulated and used, for instance, in [10] [11] [12] [13] [14]), then the wide context of discovering the physical law of conservation of energy has an axiological component. At first glance, it seems quite evident that possessing a perpetuum mobile has positive value "good". As a rule, folks believed that if the perpetuum mobile was possible, then humans would be perpetually "happy" as they would have any required quantity of energy for free. Just this proper axiological motive had been one of the most important reasons of systematical activity of crazy perpetuum-mobile constructors of all times; astonishingly immense quantity and sophisticated-ness of the crazy projects had had a concealed (yet not duly studied) proper axiological background [1]. During last centuries, the long history of the true but not absolutely obvious idea (needing justification) of impossibility of perpetuum mobile has been edited by positivist-minded scientists and deprived of proper axiological arguments. Scientific abstraction from existence of proper axiological aspect of the theme belongs to the dominating paradigm.

While searching innovative ideas in philosophical foundations of physics, let us scrutinize the prerequisites of rejecting the erroneous (although psychologically attractive) idea of perpetuum mobile. It seems verisimilar that, a fundamental prerequisite of arguments contra existence of perpetual movers has been based on a universal principle of finitism in physics. Thus, the physical law of conservation of energy is an intellectually respectable manifestation of the finitism in philosophical foundations of physics. (Even in "Physics" by Aristotle [9] there are fragments which could be considered as ancient proclamations of finitism in science of nature.) The science of nature is not one and the only in this respect. Specialists in philosophy of science are well-aware of D. Hilbert's finitism in philosophical foundations of mathematics [15]-[20]. However, the finitism in mathematics and physics deals with the totality of facts and has nothing to do with the totality of values [21]. The totality of values is studied by axiology. Abstract forms of values deprived of their concrete contents make up the subject-matter of formal axiology [10] [22]-[26]. Originally, an unknown (unhabi- 
tual) formal-axiological aspect of the finitism in philosophical grounding mathematics was highlighted as such and represented at the level of two-valued algebraic system of formal axiology in [27]. I think that finitism in philosophical foundations of physics in general (and a formal-axiological analog of it in particular) is reasonable as well. However, today the proper formal-axiological aspect of finitism in philosophical foundations of physics is almost unknown; it is not well-recognized, not well-exemplified, and not well-known as such. Strictly speaking, the proper formal-axiological aspect of finitism in philosophical foundations of physics has been formulated as such in general and exemplified by the law of conservation of energy in [11] [12] [13] [14] but yet it is almost unknown, probably, because the articles have been published in Russian language.

From a vague intuitive standpoint of finitism in philosophical grounding physics, "being of $x$ " and "conservation of finite energy of $x$ " are equivalent in some (perhaps, not quite clear) meaning of the word "equivalence". From the ground-breaking viewpoint of formal axiology of physics, the "conservation (constant-ness) of finite energy of an isolated system" can have abstract positive value "good". What does this odd combination of words mean? According to positivist-minded philosophers, for example, E. Mach [2] [28] [29] [30], R. Carnap [31] [32] [33] [34], M. Schlick [35] [36] [37], A.J. Ayer [38] [39] [40], B. Russell [41] [42] [43] [44] [45], L. Wittgenstein [21], pure axiology terms mean nothing and even blends of proper axiology terms with terms of proper physics are meaningless. However, the professional community of mathematicians and physicists is not completely reduced to positivist-minded empiricists, for example, according to A. N. Whitehead's challenging article "Mathematics and the Good" [46], proper axiology and proper mathematics are essentially connected. According to famous testimonies of many prominent physicists, mathematics has an essential connection with physics. If the testimonies of outstanding physicists are true, then, according to the challenging article by A. N. Whitehead, there is a still not recognized (or ignored on principle) essential connection of proper axiology with proper physics. At least a verisimilar hypothesis of existence of the essential connection of proper axiology with proper physics can be formulated and a set of nontrivial consequences logically following from this extraordinary hypothesis can be investigated. In the present paper, being equipped with the well-known hypothetic-deductive method, I am to examine the above-formulated extraordinary hypothesis in relation to the proper physical law of conservation of energy.

Thus, if a person abstaining from the extreme positivism asks not purely rhetorically, but seriously "What does this odd combination of proper physical and proper axiological meanings of words mean?" and sincerely desires to understand an answer to the question adequately, then it is necessary to give him precise definitions of all the notions involved in formulation of the question (and of answers to it). In physics, meanings of the words "conservation (constant-ness)", "magnitude (quantity)", "energy", "isolated", "finite" are well-known, therefore, 
it seems that there is no need to define them. Certainly, it is really so in the severely regimented professional natural-language of physics, but in natural-language as a whole, the mentioned words are homonyms. they have not one (and the only) but several significantly different meanings, among which it is possible to find even proper formal-axiological meanings of the words.

The problem of conservation of energy raised in antiquity and developed in the middle ages had not been closed forever (as finally solved) in $19^{\text {th }}$ century; it was activated as a real problem in the first quarter of $20^{\text {th }}$ century in connection with mathematical aspects of the theory of relativity [47] [48]. The problem of mathematical physics of conservation of energy was dissolved successfully by means of the two wonderful theorems (and their converses) proved by Amalia Emmy Noether [47] [48] [49] [50]. Emmy Noether's theorems gave significantly more general and profound understanding of the physical laws of conservation in general, and of the law of conservation of energy in particular. According to the above hypothetical discourse of formal-axiological aspect of pure a-priori knowledge of laws of physics, natural-language formulations of the genius theorems by Emmy Noether (and of consequences of these theorems) must have some not yet revealed formal-axiological meanings. This hypothetical affirming is based on the fact that along with the logical descriptive-indicative semantics, natural language has also a not sufficiently recognized and not well-studied formal-axiological semantics. Thus, in natural language, being homonyms, words and their combinations (standing for abstract categories) have some proper formal-axiological meanings to be revealed, defined precisely, and investigated systematically.

The formal-axiological meanings of words are evaluation-functions determined by evaluation-arguments (the formal-axiological meanings of wordcombinations are compositions of the evaluation-functions) in proper mathematical meaning of the terms: "function", "argument", and "composition (of functions)". As up to the present time precise definitions of the formal-axiological meanings of "conservation (constant-ness) of (what, whom) $x$ ", "energy of (what, whom) $x$ ", "isolated (what, who) $x$ ", "finite (what, who) $x$ ", etc. are not well-known, it is necessary to define them precisely for making the talk quite rational. In the papers [11] [12] [13] [14] all the necessary definitions are given and such a formal-axiological law which is an axiological analog of the physical law of conservation of energy is established by systematical using precise tabular definitions and accurate computing relevant compositions of evaluation-functions in two-valued algebra of formal axiology. (Being a necessary prerequisite of/for obtaining the main new result of this paper, the axiological analog of the physical law is introduced and justified by computations of evaluation-functions in paragraph 3 of the present article.)With respect to the already published in [11] [12] [13] [14] (although not well-known) axiological analog of the physical law, the following questions naturally arise. Which significantly new nontrivial scientific result hitherto not published elsewhere is to be obtained and discussed for the 
first time in the present paper? Which actual problem is to be solved finally? Which means (instruments, methods) are to be used for obtaining the result? Answers to these questions are the following.

The principal aim of the research (presented in this article) is discovering (or inventing) a formal logical (deductive) inference of the physical law of conservation of energy in a logically formalized axiomatic epistemology-and-axiology system $\Sigma$ (Sigma) from conjunction of (I) the formal-axiological analog of the physical law and (II) the assumption of a-priori-ness of knowledge. The method of obtaining the research result is discrete mathematical modeling (extracting and investigating proper algebraic aspects) and axiomatic (hypothetic-deductive) reasoning.

The scientific novelty of the main result: the above-indicated principal aim of the research has been formulated and realized in this article for the first time in the world literature on applying discrete mathematics to philosophical grounding physics. The mentioned formal deductive inference in $\Sigma$ has not been discovered (or invented) hitherto. The inference has not been published elsewhere.

However, to make the original formal inference submitted in this paper quite understandable and examinable for readers, I have included all the information indispensable for perfect understanding and rigorous scrutinizing the formal inference into the body of this article. Therefore, below in the paragraph 2, the precise definition of two-valued algebra of formal axiology is given; in the following paragraph 3, constructing the formal-axiological analog of the physical law by computing relevant evaluation-functions within the algebraic system is implemented. The paragraphs 4 and 5 make readers acquainted with strict defining the logically formalized axiomatic epistemology-and-axiology theory Sigma. The paragraph 6 of the given article contains the formal proof of such a wonderful theorem-scheme in $\Sigma$, which theorem-scheme is necessarily utilized in this paper as an effective means (instrument) for obtaining the main new scientific result not published elsewhere. The main significantly new nontrivial scientific discovery (or invention) has been accomplished below in the paragraph 7. A significantly new nontrivial theoretical statement (hitherto not yet published elsewhere) which is a byproduct (consequence) of conjunction of the main novel result of this paper and I. Kant's enigmatic statement of physicist's prescribing pure a-priori laws to nature is discussed below in the paragraph 8 . Now, having made relevant introductory remarks, we are ready to begin systematical constructing the necessary and sufficient basis for implementing the expected formal deductive inference. Let us start with extracting and investigating a proper algebraic aspect of formal axiology.

\section{Precise Defining a Two-Valued Algebraic System of Formal Axiology}

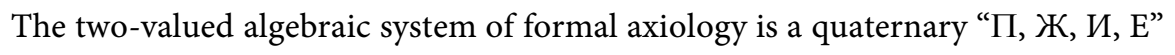
in which the symbol $\mathrm{E}$ stands for a person (individual or collective one-it does 
not matter), in relation to which all evaluations (statements of value) are generated; $\Pi$ stands for the set of all such and only such either-existing-or-not -existing things which are either good or bad ones in relation to an evaluator $\mathrm{E}$. Obviously, $\mathrm{E}$ is a variable: changing values of the variable $\mathrm{E}$ can result in changing evaluations of concrete elements of $\Pi$. However, if a value of the variable $E$ is fixed, then evaluations of concrete elements of $\Pi$ are quite definite. Elements of the set $\{g$ (good), $b$ (bad) $\}$ are called abstract formal-axiological values of elements of $\Pi$. Moral or legal acts or persons (individual or collective-it does not matter) are concrete examples (particular cases) of elements of $\Pi$. In the above-mentioned tetrad, the symbol $\nVdash$ stands for the set of all $n$-ary algebraic operations defined on the set $\Pi$. (These algebraic operations are called formal-axiological ones.) In the above-mentioned quaternary, the symbol $И$ stands for the set of all $n$-ary formal-axiological relations defined on the set $\Pi$. (For example, the below-defined "formal-axiological equivalence" and "formal-axiological entailment" belong to И.)

Algebraic operations defined on the set $\Pi$ are abstract evaluation-functions. Abstract evaluation-variables of these functions take their values from the set $\{g$, $b$ \}. Here the symbols " $g$ " and " $b$ " stand for the abstract values "good" and "bad", respectively. The functions take their values from the same set.

Speaking of abstract evaluation-functions I mean the following mappings (in the proper mathematical meaning of the word "mapping"):

$\{\mathrm{g}, \mathrm{b}\} \rightarrow\{\mathrm{g}, \mathrm{b}\}$, if one speaks of the evaluation-functions determined by one evaluation-argument;

$\{\mathrm{g}, \mathrm{b}\} \times\{\mathrm{g}, \mathrm{b}\} \rightarrow\{\mathrm{g}, \mathrm{b}\}$, where “ $\times$ ” stands for the Cartesian product of sets, if one speaks of the evaluation-functions determined by two evaluation-arguments;

$\{\mathrm{g}, \mathrm{b}\}^{N} \rightarrow\{\mathrm{g}, \mathrm{b}\}$, if one speaks of the evaluation-functions determined by $N$ evaluation-arguments, where $N$ is a finite positive integer.

The symbols " $x$ " and " $y$ " stand for abstract-value-forms of elements of $\Pi$. (Moral-value-forms of actions and persons are specific examples or particular cases of abstract-value-forms of elements of П.) Elementary abstract-value-forms deprived of their concrete contents represent independent evaluation-arguments. Compound abstract-value-forms deprived of their contents represent evaluation-functions determined by these arguments. Below let us consider some concrete examples of evaluation-functions. Naturally, all the evaluation-functions which are indispensable for realizing the aim of this article are present among the concrete examples to be introduced and defined below. Let us begin with the functions determined by one evaluation-argument. (In this paper the upper number-index 1 standing immediately after a capital letter informs that the indexed letter stands for a function determined by one argument.)

The glossary for the below-submitted Table 1 . Let the symbol $F x$ stand for the evaluation-function "finite, definite, limited (what, who) $x$ " or "finiteness, definiteness, limitedness of (what, whom) $x^{\prime \prime} . D^{1} x$ stands for the evaluationfunction "infinite, indefinite, unlimited (what) $x$ " or “infiniteness, indefiniteness 
of $X^{\prime} . K^{1} X$ stands for the evaluation-function "quantity (magnitude) of $X^{\text {" }} \cdot L^{1} X-$ "necessity of $X^{\prime} . Z^{1} X^{-}$"impossibility of $X^{\prime} . P^{1}{ }^{x}$ " "possibility of $X^{\prime} . W^{\dagger} X^{-}$" change, flow, movement, locomotion of $X$ ", or "moving (what, whom) $X$ ", or "mover

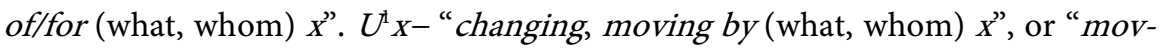
er (what, who) $X^{\prime}$. $R^{1} X^{-}$"primum mobile (the first mover) of/for $X^{\prime}, X^{1} X^{-}$ "self-change, self-movement of or by (what, whom) $X^{\prime} . M^{1} X^{-}$"matter, material (what, who) $x$ " or "materialness of $x^{\prime} . V^{4} x$ - "dividing (what, whom) $x$ " or "dividedness of $x^{\prime}$. $f^{1} X^{-}$"indivisibility of $x^{\prime}$. The introduced evaluation-functions are defined by the following Table 1 .

The glossary for the below-submitted Table 2: $A^{1}{ }^{X-}$ "time of $X$ in generaP", or "metaphysical time of $x^{\prime} \cdot T^{1} x$ - "physical (relative) time of $x^{\prime} . G^{1} x$ - "homogeneity, uniformity of (what, whom) $X^{\prime} . B^{1} X^{1}$ " "being (existence) of $X^{\prime} . N^{\mathrm{t}} X^{-}$" nonbeing (nonexistence) of $x^{\prime} . O^{1} x-$ "an opposite of/for $x^{\prime} . Q^{1} x-$ "penetration into $x^{\prime}$ or "penetrability of $x^{\prime} . Y^{1}{ }^{X}$ - "impenetrability of $X^{\prime} . I^{1}{ }^{1}$ - "isolated, closed, protected (what, who) $x$ " or "isolated-ness, closed-ness, protected-ness of $x$ ". $C x$ - "conservation, preservation of (what, whom) $x$ " or " $x$ 's being unchangeable, immutable, constant", or "immovability, immutability, constant-ness of $x^{\prime} . H^{1} x-$ "self-conservation of or by (what, whom) $x^{\prime}$. $E^{1} x^{-}$" energy of $x . S^{1} X^{-}$"sensation (feeling), sensual perception of $x$ (as an object). The introduced evaluation-functions are defined by the following Table 2 .

Initially, the tabular definitions of evaluation-functional sense of the aboveintroduced unary operations of two-valued algebra of formal axiology were published in [10] [27] [12] [13] [51] [52]. Now let us introduce and define some binaryoperations of the algebraic system of formal axiology.

The glossary for the below-submitted Table 3: (In this paper the upper number-index 2 standing immediately after a capital letter informs that the indexed letter stands for a function determined by $t w o$ arguments.) Let the symbol $W^{\mathcal{2}} x y$ stand for the evaluation-function "change, movement, locomotion of $x$ by (what, whom) $y$ ", or "mover (what, who) $y$ of/for $x . M^{2} x y$ stands for the evaluation-function " $x$ 's being a matter, material for (what, whom) $y$ ", or "materialness of $x$ for $y^{\prime \prime} . N^{z} x y$ - the evaluation-function "nonbeing of $x$ for (what, whom) $y$ ". $F^{2} x y$ - the evaluation-function "finiteness of $x$ for (what, whom) $y$ ". $T^{2} x y-$ "termination, annihilation, destruction of $x$ by (what, whom) $y$ ". $C^{2} x y-$ "conservation,

Table 1. The functions determined by one argument.

\begin{tabular}{cccccccccccccc}
\hline $\boldsymbol{x}$ & $\boldsymbol{F}^{\mathrm{1}} \boldsymbol{x}$ & $\boldsymbol{D}^{\mathrm{1}} \boldsymbol{x}$ & $\boldsymbol{K}^{\mathrm{1}} \boldsymbol{x}$ & $\boldsymbol{L}^{1} \boldsymbol{x}$ & $\boldsymbol{Z}^{\mathrm{1}} \boldsymbol{x}$ & $\boldsymbol{P}^{\mathrm{l}} \boldsymbol{x}$ & $\boldsymbol{W}^{\mathrm{1}} \boldsymbol{x}$ & $\boldsymbol{U}^{\mathrm{1}} \boldsymbol{x}$ & $\boldsymbol{R}^{1} \boldsymbol{x}$ & $\boldsymbol{X}^{\mathrm{1}} \boldsymbol{x}$ & $\boldsymbol{M}^{\mathrm{1}} \boldsymbol{x}$ & $\boldsymbol{V}^{\mathrm{1}} \boldsymbol{x}$ & $\boldsymbol{f}^{\mathrm{1}} \boldsymbol{x}$ \\
\hline $\mathrm{g}$ & $\mathrm{b}$ & $\mathrm{g}$ & $\mathrm{g}$ & $\mathrm{g}$ & $\mathrm{b}$ & $\mathrm{g}$ & $\mathrm{b}$ & $\mathrm{g}$ & $\mathrm{g}$ & $\mathrm{b}$ & $\mathrm{b}$ & $\mathrm{b}$ & $\mathrm{g}$ \\
$\mathrm{b}$ & $\mathrm{g}$ & $\mathrm{b}$ & $\mathrm{b}$ & $\mathrm{b}$ & $\mathrm{g}$ & $\mathrm{b}$ & $\mathrm{g}$ & $\mathrm{b}$ & $\mathrm{g}$ & $\mathrm{b}$ & $\mathrm{g}$ & $\mathrm{g}$ & $\mathrm{b}$ \\
\hline
\end{tabular}

Table 2. The one-placed evaluation-functions.

\begin{tabular}{cccccccccccccc}
\hline $\boldsymbol{x}$ & $\boldsymbol{A}^{1} \boldsymbol{x}$ & $\boldsymbol{T}^{1} \boldsymbol{x}$ & $\boldsymbol{G}^{1} \boldsymbol{x}$ & $\boldsymbol{B}^{1} \boldsymbol{x}$ & $\boldsymbol{N}^{1} \boldsymbol{x}$ & $\boldsymbol{O}^{1} \boldsymbol{x}$ & $Q^{1} \boldsymbol{x}$ & $\boldsymbol{Y}^{1} \boldsymbol{x}$ & $\boldsymbol{I}^{1} \boldsymbol{x}$ & $\boldsymbol{C}^{\boldsymbol{x}} \boldsymbol{x}$ & $\boldsymbol{H}^{1} \boldsymbol{x}$ & $\boldsymbol{E}^{1} \boldsymbol{x}$ & $\boldsymbol{S}^{1} \boldsymbol{x}$ \\
\hline $\mathrm{g}$ & $\mathrm{g}$ & $\mathrm{b}$ & $\mathrm{g}$ & $\mathrm{g}$ & $\mathrm{b}$ & $\mathrm{b}$ & $\mathrm{b}$ & $\mathrm{g}$ & $\mathrm{g}$ & $\mathrm{g}$ & $\mathrm{g}$ & $\mathrm{b}$ & $\mathrm{b}$ \\
$\mathrm{b}$ & $\mathrm{b}$ & $\mathrm{g}$ & $\mathrm{b}$ & $\mathrm{b}$ & $\mathrm{g}$ & $\mathrm{g}$ & $\mathrm{g}$ & $\mathrm{b}$ & $\mathrm{b}$ & $\mathrm{b}$ & $\mathrm{g}$ & $\mathrm{g}$ & $\mathrm{g}$ \\
\hline
\end{tabular}


preservation, protection, defense of $x$ by $y$ ". $L^{2} x y$ - "necessity of $y$ for $x " . P^{2} x y-$ "possibility of $y$ for $x$ ". These functions are defined by the following Table 3. Also, one can find tabular definitions of these functions in [10] [23] [24] [25] [26] [51] [52].

The glossary for the below-submitted Table 4: $Y^{2} x y-$ "impossibility of $y$ for $x^{\prime} . E^{2} x y-$ "axiological equivalence (identity of values) of $x$ and $y^{\prime} . D^{2} x y-" d e$ pendence of $x$ from $y$ ". $P^{2} x y-$ "independence of $x$ from $y$ ". $Z^{2} x y-$ "contradiction of $y$ to (or with) $y$ ". $K^{2} x y$ - "unity (one-ness) of $x$ and $y$ ", or "joint being of $x$ and $y$ ", or " $x$ and $y$ being together". $B^{2} x y-$ "being of $y$ in $x$ ". $A^{2} x y-$ "mutual annihilation of $x$ and $y$ ". These functions are defined by the following Table 4. Also, one can find tabular definitions of these functions in [10] [23] [24] [25] [26] [51] [52].

The notions: "formal-axiological equivalence"; "formal-axiological contradiction"; "formal-axiological law"; "formal-axiological-entailment" in the two-valued algebraic system of formal axiology are precisely defined as follows.

Definition DEF-1 of the two-placed relation called "formal-axiological-equivalence": in the algebraic system of formal axiology, any evaluation-functions $\Xi$ and $\Theta$ are formally-axiologically equivalent (this is represented by the expression “ $\Xi=+=\Theta$ ”), if and only if they acquire identical axiological values (from the set $\{g$ (good), $b(\mathrm{bad})\})$ under any possible combination of the values of their evaluation-variables.

Definition DEF-2 of the notion "formal-axiological law": in algebra of formal axiology, any evaluation-function $\Theta$ is called formally-axiologically (or necessarily, or universally, or absolutely) good one, or a law of algebra of formal axiology (or a "law of algebra of metaphysics"), if and only if $\Theta$ acquires the value $g$ (good) under any possible combination of the values of its evaluation-variables. In other words, the function $\Theta$ is formally-axiologically (or constantly) good one, iff $\Theta=+=$ g (good).

Table 3. The functions determined by two arguments.

\begin{tabular}{cccccccccc}
\hline $\boldsymbol{x}$ & $\boldsymbol{y}$ & $W^{2} x y$ & $M^{2} x y$ & $N^{2} x y$ & $F^{2} x y$ & $T^{2} x y$ & $C^{2} x y$ & $L^{2} x y$ & $P^{2} x y$ \\
\hline $\mathrm{g}$ & $\mathrm{g}$ & $\mathrm{b}$ & $\mathrm{b}$ & $\mathrm{b}$ & $\mathrm{b}$ & $\mathrm{b}$ & $\mathrm{g}$ & $\mathrm{b}$ & $\mathrm{g}$ \\
$\mathrm{g}$ & $\mathrm{b}$ & $\mathrm{b}$ & $\mathrm{b}$ & $\mathrm{b}$ & $\mathrm{b}$ & $\mathrm{b}$ & $\mathrm{g}$ & $\mathrm{b}$ & $\mathrm{g}$ \\
$\mathrm{b}$ & $\mathrm{g}$ & $\mathrm{g}$ & $\mathrm{g}$ & $\mathrm{g}$ & $\mathrm{g}$ & $\mathrm{g}$ & $\mathrm{b}$ & $\mathrm{g}$ & $\mathrm{g}$ \\
$\mathrm{b}$ & $\mathrm{b}$ & $\mathrm{b}$ & $\mathrm{b}$ & $\mathrm{b}$ & $\mathrm{b}$ & $\mathrm{b}$ & $\mathrm{g}$ & $\mathrm{b}$ & $\mathrm{b}$ \\
\hline
\end{tabular}

Table 4. The two-placed evaluation-functions.

\begin{tabular}{|c|c|c|c|c|c|c|c|c|c|}
\hline$x$ & $y$ & $Y^{2} x y$ & $E^{2} x y$ & $D^{2} x y$ & $P_{x y}$ & $Z^{2} x y$ & $K^{2} x y$ & $B^{2} x y$ & $A^{2} x y$ \\
\hline g & g & $\mathrm{b}$ & g & $\mathrm{b}$ & g & $\mathrm{b}$ & g & g & $\mathrm{b}$ \\
\hline g & $\mathrm{b}$ & $\mathrm{b}$ & $\mathrm{b}$ & $\mathrm{b}$ & $\mathrm{g}$ & b & $\mathrm{b}$ & b & $\mathrm{b}$ \\
\hline b & g & $\mathrm{b}$ & $\mathrm{b}$ & g & $\mathrm{b}$ & g & $\mathrm{b}$ & g & $\mathrm{b}$ \\
\hline $\mathrm{b}$ & $\mathrm{b}$ & $\mathrm{g}$ & $\mathrm{g}$ & $\mathrm{b}$ & $\mathrm{g}$ & $\mathrm{b}$ & $\mathrm{b}$ & g & $\mathrm{g}$ \\
\hline
\end{tabular}


Definition DEF-3 of the notion "formal-axiological contradiction": in algebra of formal axiology, any evaluation-function $\Theta$ is called formally-axiologically (or invariantly, or absolutely) bad one, or a "formal-axiological contradiction", if and only if $\Theta$ acquires the value $b$ (bad) under any possible combination of the values of its evaluation-variables. In other words, the function $\Theta$ is formally-axiologically (or necessarily, or universally, or absolutely) bad one, iff $\Theta=+=\mathrm{b}$ (bad).

Definition DEF-4 of the two-placed relation called "formal-axiological-entailment": in the algebraic system of formal axiology, for any evaluation-functions $\Xi$ and $\Theta$, it is true that " $\Theta$ formally-axiologically follows from $\Xi$ ", iff $C^{2} \Xi \Theta=+=$ g (good).

With respect to the above-given definition-DEF-1, here it is worth mentioning and emphasizing that in the ambiguous natural language, very often the relation " $\Xi=+=\Theta$ " is represented by the words-homonyms "is", "means", "implies", "entails", "equivalence" (They may stand for the formal-axiological equivalence relation "=+="). As in the ordinary natural language the words "is", "means", "implies", "equivalence", etc. also may stand for the logic operations "equivalence" and "implication", there is a real possibility of confusions produced by absolute identifying and, hence, substituting for each other the substantially different notions " $=+=$ " and logic operation "equivalence" (or " $=+=$ " and logic operation "implication"). Such mixing and substituting are strictly forbidden in the above-defined algebra of formal axiology. Ignoring this ban indispensably leads to paradoxical results.

Taking into an account the above-given definitions, one can make an important discovery: the invariant laws (formal-axiological ones) of the algebraic system of formal axiology do not depend upon possible changes of evaluator E. If $\Theta$ is a formal-axiological law, then $\Theta$ is good in relation to every evaluator $\mathrm{E}$. Moreover, formal-axiological contradictions also do not depend upon possible changes of the evaluator $\mathrm{E}$. If $\Theta$ is a formal-axiological contradiction, then $\Theta$ is bad in relation to every evaluator E. Finally, if there is the above-defined formal-axiological equivalence relation between evaluation-functions $\Xi$ and $\Theta$, then the functions $\Xi$ and $\Theta$ are formally-axiologically equivalent ones in relation to every evaluator E. Hence, in spite of the evident flexibility and obvious relativity of empirical evaluations, there are absolute invariants (immutable universal laws) of the evaluation relativity. Thus, the evaluation relativity is not an absolutely unsolvable problem as the relativity is not absolute but relative one [53].

Concerning the above-said there is one more theme worthy of mentioning. From the viewpoint of pure mathematics, in the two-valued algebra of formalaxiology there are 4 (and only 4) mathematically different unary formal-axiological operations (namely, two mutually opposite constant-functions and two mutually opposite not-constant-functions). However, in this paper I deal with more than 4 different unary formal-axiological operations. This is so because their difference is not purely mathematical one: it comes from the field of application of the mathematical apparatus, namely, from the contents of metaphysics (interpreted) 
as a strictly universal theory of abstract-value-forms. Hence the more-than-fourelement-set of unary formal-axiological operations considered in this paper is divided into four subsets, and within each of the four subsets any elements are formally-axiologically equivalent to each other. Thus, there is no inconsistency. Here it is also worth making the analogous remark in relation to the binary formal-axiological operations of the two-valued formal-axiology algebra.

Now the preparatory work is finished: the set of basic definitions necessary and sufficient for generating equations in the algebraic system and, especially, for precise formulating and computational demonstrating an unhabitual formal-axiological-law of conservation of energy by means of the artificial language and conceptual apparatus of two-valued algebra of formal-axiology is already presented. Therefore, let us start generating a finite list of algebraic equations relevant to the theme of this article by computing compositions of relevant evaluation-functions in algebra of axiology.

\section{A Wonderful Law of Two-valued Algebra of Formal-Axiology Which Algebraic Law Is Significantly Analogous (Very Similar) to the Great Law of Conservation of Energy in Physics}

According to R. P. Feynman, in our time the famous law of conservation of energy belongs to the set of great laws of conservation in physics [54]. The law, which effectively unites and organizes immense empirical material of physics, is a strictly universal statement of what is (necessarily) in nature. All the hitherto-suggested formulations of the law are not ones of what is good (necessarily) in nature. This is so because contemporary statements of energy conservation law in proper physics are quite reasonable scientific abstractions from any answers to the queer question of existence of a formal-axiological aspect of the great law. Nevertheless, for the first time in history of philosophy of physics, in [11] [12] [13] [14] it has been shown that by accurate computing compositions of relevant evaluation-functions in two-valued algebra of formal axiology, one can discover, examine, and recognize such a psychologically unexpected formal law of two-valued algebra of abstract values, which wonderful law (being translated from the artificial language of the two-valued mathematical model of formal axiology into natural language of humans) looks like a natural-language formulation of the law of conservation of energy in proper physics. Consequently, along with the well-known purely ontological and epistemological aspects of the great conservation law, an almost unknown formal-axiological aspect of it does exist necessarily.

Obviously, the great law of conservation of energy is not reduced to its quite extraordinary (unhabitual and queer) formal-axiological aspect. Certainly, the habitual ontological and epistemological aspects of the law exist as well. Hence, from the abstract theory standpoint, there is a strong need to unite logically the three aspects in one coherent system. Therefore, in particular, with respect to philosophy of physics, there is a strong theoretical need to attempt formal- 
ly-logically (deductively) to infer the great law of conservation in physics from its formal-axiological analog, in some logically formalized axiomatic axiology-ontology-and-epistemology system (probably, under some special epistemological assumption).

Such formal-logical (deductive) deriving the proper-theoretical-physics-law of conservation of energy from its formal-axiological analog in the formal axiomatic system $\Sigma$ (under the epistemological assumption of a-priori-ness of knowledge) is realized below in the present article for the first time in world literature on philosophy and physics. Hitherto this article has not been published elsewhere.

However, to make the mentioned substantially new nontrivial scientific result quite understandable and examinable for readers, it is necessary to make the readers acquainted with the formal-axiological analog of the law of conservation of energy by constructing this analog. To make this acquaintance by constructing the formal-axiological analog, let us consider the following list of formal-axiological equations generated by computing compositions of evaluation-functions according to the definitions given above in the paragraph 2. Every element of the below succession is an equation of two-valued formal-axiology algebra. To the left from each equation (after the colon), a translation of the equation from artificial language into natural one is given. The translations are performed by means of the above-presented glossaries for Tables 1-4. The equations are results of accurate computing compositions of the functions defined by Tables 1-4. Therefore, in principle, the results of computations and translations are examinable by the readers who are accommodated to the definitions.

1) $B^{\mathrm{l}} x=+=N^{\natural} W^{\mathrm{t}} x$. being of $x$ is nonbeing of movement of $x$ (Parmenides and Zeno of Elea, Melissus of Samos [55].)

2) $B^{1} x=+=Z^{1} W^{t} x$. being of $x$ is impossibility of movement of $x$ (Parmenides and Zeno of Elea, Melissus of Samos [55].)

3) $U^{4} x=+=O^{1} W^{\lambda} x$. moving by $x$ (i.e. $x^{3}$ s being a mover) is an opposite of/for movement of $x$. (This equation is a model of/for Aristotle's discourse of primum mobile in his "Physics" [9]).

4) $U^{\lambda} x=+=N^{\lambda} W^{\lambda} x$ : $x^{\prime}$ s being a mover is equivalent to nonbeing of movement of $x$. (This equation is a model of/for Aristotle's talks of the first mover [9]).

5) $X^{1} x=+=W^{2} x X=+=$ b: self-movement is a formal-axiological contradiction.

6) $B^{1} x=+=Z^{1} D^{1} W^{1} x$. being of $x$ is impossibility of infinite movement of $x$.

7) $B^{\mathrm{l}} X=+=P^{\mathrm{l}} F^{\mathrm{l}} W^{\mathrm{l}} x$. being of $x$ is possibility of finite movement of $x$.

8) $B^{\mathrm{l}} x=+=U^{\mathrm{A}} x$. being of $x$ is moving by $x$ (i.e. $x^{2}$ s being a mover).

9) $D^{1} B^{1} x=+=D^{1} U^{\mathrm{t}} x$. infinite being of $x$ is infinite moving by $x$.

10) $F B^{1} x=+=F U^{1} x$. finite being of $x$ is finite moving by $x$.

11) $F x=+=Z D^{1} U^{4} x$. finiteness of $x$ means impossibility of infinite moving by $x$.

12) $F_{X=+} x=F^{4} U^{4} x$. finiteness of $x$ implies finiteness of $x^{2}$ s being a mover.

13) $M^{\mathrm{l}} x=+=Z^{\mathrm{l}} D^{1} U^{\mathrm{l}} x$. materialness of $x$ means impossibility of infinite moving 
by $x$.

14) $M^{1} x=+=F^{1} U^{1} x$ : materialness of $x$ implies finiteness of $x^{\prime}$ s being a mover.

15) $E^{1} x=+=P^{l} W^{1} x$. energy of $x$ is nothing but possibility of motion of $x$. (This equation could be used as a definition of $E x$.)

16) $B^{1} x=+=Z^{1} D^{1} E^{1} x$. being of $x$ is impossibility of infinite energy of $x$.

17) $B^{1} x=+=L^{1} F^{1} E^{1} x$. being of $x$ is necessity of finiteness of energy of $x$.

18) $B^{\mathrm{l}} x=+=F^{1} E^{1} x$. being of $x$ is finiteness of energy of $x$.

19) $B^{1} x=+=F^{1} K^{1} E^{1} x$. being of $x$ is finiteness of quantity (magnitude) of energy of $x$.

20) $B^{\mathrm{l}} x=+=C F^{\mathrm{i}} K^{1} E^{\mathrm{1}} x$. being of $x$ is conservation (constant-ness, immutability) of finite magnitude (quantity) of energy of $x$.

21) $B^{1} x=+=I^{1} x$ : being of $x$ is equivalent to isolated-ness, closed-ness, protected-ness of $x$.

22) $I^{1} X=+=C F K^{1} E^{1} x$ isolated-ness, closed-ness of $x$ is equivalent to conservation (constant-ness, immutability) of finite magnitude (quantity) of energy of $x$.

23) $E^{2} I^{1} x C F^{1} K^{1} E^{1} x=+=$ g: equalizing (identifying values) of $I^{1} x$ and $C F^{1} K^{1} E^{1} x$ is a law of two-valued algebra of formal-axiology.

24) $I^{1} F_{X=+}^{\mathrm{A}}=Z D^{\mathrm{l}} U^{\mathrm{l}} x$ : isolated-ness of a finite $x$ is equivalent to impossibility of infinite moving by $x$. (This means impossibility of the perpetuum mobile.)

25) $I^{1} M^{1} x=+=Z^{1} D^{1} U^{4} x$. isolated-ness of a material $x$ is equivalent to impossibility of infinite moving by $x$.

26) $B^{1} x=+=N^{1} D^{1} W^{4} x$. being of $x$ is nonbeing of perpetual mover of/for $x$.

27) $B^{1} x=+=Z^{1} D^{1} W^{1} x$. being of $x$ is impossibility of perpetuum mobile of/for $x$.

28) $B^{1} x=+=P^{l} F^{1} W^{1} x$. being of $x$ is possibility of finite mover of/for $x$.

29) $U^{1} x=+=O^{1} W^{1} x$. mover (what, who) $x$ is an opposite of mover of/for $x$.

30) $D^{1} X^{1} y=+=D^{1} W^{2} y y=+=$ b: infinite self-motion of $y$ (i.e. infinite $y^{\prime}$ s being a mover of/for $y$ ) is a formal-axiological contradiction (in two-valued algebra under investigation).

31) $Z^{1} D^{1} X^{1} y=+=Z 1 D^{1} W^{2} y y=+=$ g: impossibility of infinite self-movement is a formal-axiological law (in two-valued algebra under investigation).

32) $P^{1} F^{1} W^{2} y y=+=g$ : possibility of finite self-movement is a formal-axiological law.

33) $B^{1} F^{1} W^{2} y y=+=$ g: existence of finite self-movement is a formal-axiological law.

34) $F X^{\mathrm{t}} y=+=F^{1} W^{2} y y=+=\mathrm{g}$ : finite self-movement is a formal-axiological law.

35) $W^{1} R^{1} X=+=$ b: movement of the primum mobile is a formal-axiological contradiction (This is a model of/for Aristotle's "Physics" [9]).

36) $Z^{1} W^{1} R^{1} x_{=+=}$: impossibility of the primum mobile being moved is a formal-axiological law.

37) $N^{\dagger} M^{1} R^{1} x=+=g$ : immaterialness of the primum mobile is a formal-axiological law.

38) $D^{1} R^{1} x=+=$ g: infiniteness (perpetual-ness) of the primum mobile is a formal-axiological law.

39) $F^{1} x=+=F U^{\lambda} x$. finiteness of $x$ is equivalent to finiteness of moving by $x$, i.e. 
to finiteness of $x^{\prime}$ s being a mover.

40) $H^{1} x=+=O^{1} X^{1} x$. self-conservation of (or by) $x$ is an opposite of/for self-change, self-motion of (or by) $x$.

41) $H^{1} x=+=C^{2} x=+=g$ : self-conservation of (or by) $x$ is a formal-axiological law.

42) $C^{2} x y=+=P^{2} x y$. conservation of $x$ by $y$ is formally-axiologically equivalent to independence of $x$ from $y$.

43) $I^{2} F^{1} K^{1} E^{1} I^{1} x W^{\lambda} T^{1} x=+=$ g: independence of finite quantity of energy of isolated $x$ from change (flow) of physical time of $x$ is a formal-axiological law. This hitherto never published equation of two-valued algebra of metaphysics as formal axiology is a discrete mathematical model of an unknown formal-axiological aspect of the famous theorem by Amalie Emmy Noether [47] [48] [49] [50]. Although, factually, A.E. Noether did not deal with discrete (two-valued) mathematical model of formal axiology as such, the relevant formulation of her great theorem in natural-language has a formal-axiological meaning not yet recognized as such and not yet modeled mathematically. In this respect, the present innovative article is a challenge for the dominating paradigm.

44) $C^{2} F^{1} K^{1} E^{1} I^{1} x W^{4} T^{1} x=+=$ g: conservation of finite quantity of energy of isolated $x$ by flow of physical time of $x$ is a formal-axiological law. This is a nontrivial scientific novelty discovered in the given article first-ever by accurate computing compositions of relevant evaluation-functions.

45) $G^{1} T^{1} x=+=C F^{1} K^{1} E^{1} I^{1} M^{1} x$ : uniformity (homogeneity) of physical time of $x$ implies conservation of finite quantity of energy of isolated material $x$.

46) $G^{1} A^{1} x=+=C F^{1} E^{1} I^{1} x$ : uniformity (homogeneity) of time of $x$ implies conservation of finite quantity of energy of isolated $x$.

47) $Z^{1} D^{1} W^{\mathrm{t}} x^{-1}=C F^{1} K^{1} E^{1} I^{1} x$ : impossibility of perpetual mover of/for $x$ is equivalent to constant-ness of finite quantity of energy of isolated $x$. Thus, the "principle of impossibility of perpetuum mobile" and the "law of conservation of energy" are somewhat different natural-language formulations of one and the same.

The main novelty of the work here (in the paragraph 3 of the paper) is presented by the formal-axiological equivalences 22) and 23) which are discrete mathematical models of the formal-axiological law of conservation of energy which law is a formal-axiological analog of the corresponding necessarily universal law of physics proper.

Originally, the formal-axiological equivalence of "existence" and "impossibility of perpetuum mobile" was published in [10] [56]. For the first time, the formal-axiological law of conservation of energy was published in [11] [12] [13] [14]. At first glance, it seems that the elements 22) and 23) of the above-placed list of formal-axiological equivalences mean nothing but the well-known law of conservation of energy in physics, therefore, it seems that the equations 22) and 23) (in the above list) represent nothing qualitatively novel for proper physics and for its philosophical foundations as well. However, in my opinion, it only seems so. The translation of the indicated formal-axiological equations from the 
artificial language of algebra of formal-axiology into the ambiguous natural language of humans looks like human-natural-language formulations of the law of conservation of energy in physics, but actually they are not statements of being but formal-axiological statements of value (while the law of conservation of energy in physics is a statement of being).

In some concrete relation, the natural-language formulations of the two (the law of conservation of energy in physics and the formal-axiological analog of it) are really similar (the combinations of words are identical) but due to homonymy of the words, meanings of their combinations are not identical. In contrast to the natural-language formulation of the energy-conservation-law of physics, the natural-language formulation of the corresponding law of two-valued algebra of formal axiology has formal-axiological semantics which is significantly different (and in some respect independent) from the logical semantics of descriptive-indicative propositions of empirical physics. The contemporary theoretical physics has investigated "what is (or is not) necessarily" in nature. According to its core idea, the hypothetical formal axiology of nature investigates "what is good (or bad) necessarily" in nature. According to the well-known principle called "Hume Guillotine" and to the well-known Moore's doctrine of naturalistic fallacies in ethics, elements of the couples "is"; "is obligatory" and "is"; "is good" are logically independent: formal logical inferences between elements of these couples are not well-grounded. With respect to some habitual concrete relation which statistically normal humans are used to, namely, concerning proper empirical knowledge, it is really so: the gap between "is" and "is good" ("is" and "is obligatory") is logically unbridgeable.

Notwithstanding this, in result of systematical investigating some not-habitual concrete relations, rare conditions, extraordinary circumstances and psychologically paradoxical arguments, I have arrived to a psychologically unexpected (surprising) hypothesis that under some very rare extraordinary condition, the notorious gap (allegedly called logically unbridgeable one) between "is" and "is good" (or "is" and "is obligatory") can be bridged logically. Certainly, this paradigm-breaking hypothesis can be false one to be rejected resolutely in spite of its being beautiful and intuitively attractive to its creator. Taking this possibility seriously, instead of usual philosophical wrangling and insulting the hypothesis creator, let us move tranquilly to the next part of the article for precise formulating, formal demonstrating, and rigorous scrutinizing the odd hypothesis before its possible rejection.

Below in this paper, within the logically formalized axiomatic theory $\Sigma$ published, for instance, in [52] [57], I am to submit a formal deductive inference of the law of conservation of energy in physics from conjunction of (I) the above-constructed formal-axiological analog of the energy-conservation law of physics and (II) the assumption of a-priori-ness of knowledge. As below in this article the theory $\Sigma$ is necessarily used as a means of/for obtaining a significantly new hitherto not published nontrivial result, I have to repeat (recall) the exact definition of $\Sigma$ in the immediately following part of the paper for making readers 
able adequately to understand and rigorously to scrutinize the for-the-firsttime-submitted formal deductive derivation of the law of conservation of energy (as the well-known law of physics proper) in $\Sigma$ from the above-mentioned conjunction of premises.

\section{Defining Formal Axiomatic Epistemology-and-Axiology Theory Sigma}

The theory $\Sigma$ is an outcome of further developing an option of axiomatizing universal philosophical epistemology suggested in [58] [59] [60]. By definition, the logically formalized axiomatic epistemology-and-axiology theory $\Sigma$ contains all symbols (of the alphabet), expressions, formulae, axioms, and inference-rules of the formal axiomatic epistemology theory $\Xi[60]$ which is based on the classical propositional logic. But in $\Sigma$ several significant aspects are added to the formal theory $\Xi$. In result of these additions the alphabet of $\Sigma$ 's object-language is defined as follows:

1) Small Latin letters $q, p, d$ (and the same letters possessing lower number indexes) are symbols belonging to the alphabet of object-language of $\Sigma$; they are called "propositional letters". Not all small Latin letters are proposition al ones in the alphabet of $\Sigma$ 's object-language, as, by this definition, small Latin letters belonging to the set $\{\mathrm{g}, \mathrm{b}, \mathrm{e}, \mathrm{n}, \mathrm{x}, \mathrm{y}, \mathrm{z}, \mathrm{t}, \mathrm{f}\}$ are excluded from the set of propositional letters.

2) Logic symbols $\neg, \supset, \leftrightarrow, \&, \vee$ called "classical negation", "material implication", "equivalence", "conjunction", "not-excluding disjunction”, respectively, are symbols belonging to $\Sigma$ 's object-language alphabet.

3) Elements of the set of modality-symbols $\{\square, K, A, E, S, T, F, P, Z, G, W, O$, $\mathrm{B}, \mathrm{U}, \mathrm{Y}\}$ belong to $\Sigma$ 's object-language alphabet.

4) Technical symbols "(" and ")" called "round brackets" belong to $\Sigma$ 's object-language alphabet. The round brackets are exploited in this paper as usually in symbolic logic.

5) Small Latin letters $x, y, z$ (and the same letters possessing lower number indexes) are symbols belonging to $\Sigma$ 's object-language-alphabet (they are called “axiological variables").

6) Small Latin letters "g" and "b" called axiological constants belong to the alphabet of object-language of $\Sigma$.

7) The capital Latin letters possessing number indexes $\mathrm{K}^{1}, \mathrm{E}^{1}, \mathrm{C}^{1}, \mathrm{~K}^{2}, \mathrm{E}^{2}, \mathrm{C}^{2}, \mathrm{~A}_{\mathrm{k}}^{\mathrm{n}}, \mathrm{B}_{\mathrm{i}}^{\mathrm{n}}, \mathrm{C}_{\mathrm{j}}^{\mathrm{n}}, \mathrm{D}_{\mathrm{m}}^{\mathrm{n}}, \cdots$ belong to the object-language-alphabet of $\Sigma$ (they are called "axiological-value-functional symbols"). The upper number index $n$ informs that the indexed symbol is $n$-placed one. Nonbeing of the upper number index informs that the symbol is determined by one axiological variable. The value-functional symbols may have no lower number index. If lower number indexes are different, then the indexed functional symbols are different ones.

8) Symbols "[" and "]" ("square brackets") also belong to the object-languagealphabet of $\Sigma$, but in this theory they are exploited in a very unusual way. Al- 
though, from the psychological viewpoint, square brackets and round ones look approximately identical and are used very often as synonyms, in the present article they have qualitatively different meanings (roles): exploiting round brackets is purely technical as usually in symbolic logic; square-bracketing has an ontological meaning which is to be defined below while dealing with semantic aspect of $\Sigma$. Moreover, even at syntax level of $\Sigma$ 's object-language, being not purely technical symbols, square brackets play a very important role in the below-given definition of the general notion "formula of $\Sigma$ " and in the below-given formulations of some axiom-schemes of $\Sigma$.

9) An unusual artificial symbol "=+=" called "formal-axiological equivalence" belongs to the alphabet of object-language of $\Sigma$. The symbol "=+=" also plays a very important role in the below-given definition of the general notion "formula of $\Sigma$ " and in the below-given formulations of some axiom-schemes of $\Sigma$.

10) A symbol belongs to the alphabet of object-language of $\Sigma$, if and only if this is so owing to the above-given items 1) - 9) of the present definition.

A finite succession of symbols is called an expression in the object-language of $\Sigma$, if and only if this succession contains such and only such symbols which belong to the above-defined alphabet of $\Sigma$ 's object-language.

Now let us define precisely the general notion "term of $\Sigma$ ":

1) the axiological variables (from the above-defined alphabet) are terms of $\Sigma$;

2) the axiological constants belonging to the alphabet of $\Sigma$, are terms of $\Sigma$;

3) If $\Phi_{\mathrm{k}}^{\mathrm{n}}$ is an n-placed axiological-value-functional symbol from the above-defined alphabet of $\Sigma$, and $\mathrm{t}_{\mathrm{i}}, \cdots, \mathrm{t}_{\mathrm{n}}$ are terms (of $\Sigma$ ), then $\Phi_{\mathrm{k}}^{\mathrm{n}} \mathrm{t}_{\mathrm{i}}, \cdots, \mathrm{t}_{\mathrm{n}}$ is a term (compound one) of $\Sigma$ (here it is worth remarking that symbols $t_{i}, \cdots, t_{n}$ belong to the meta-language, as they stand for any terms of $\Sigma$; the analogous remark may be made in relation to the symbol $\Phi_{k}^{\mathrm{n}}$ which also belongs to the meta-language);

4) An expression in object-language of $\Sigma$ is a term of $\Sigma$, if and only if this is so owing to the above-given items 1) - 3) of the present definition.

Now let us make an agreement that in the present paper, small Greek letters $\alpha$, $\beta$, and $\gamma$ (belonging to meta-language) stand for any formulae of $\Sigma$. By means of this agreement the general notion "formulae of $\Sigma$ " is defined precisely as follows.

1) All the above-mentioned propositional letters are formulae of $\Sigma$.

2) If $\alpha$ and $\beta$ are formulae of $\Sigma$, then all such expressions of the object-language of $\Sigma$, which possess logic forms $\neg \alpha,(\alpha \supset \beta),(\alpha \leftrightarrow \beta),(\alpha \& \beta),(\alpha \vee \beta)$, are formulae of $\Sigma$ as well.

3) If $t_{i}$ and $t_{k}$ are terms of $\Sigma$, then $\left(t_{i}=+=t_{k}\right)$ is a formula of $\Sigma$.

4) If $t_{i}$ is a term of $\Sigma$, then $\left[t_{i}\right]$ is a formula of $\Sigma$.

5) If $\alpha$ is a formula of $\Sigma$, and meta-language-symbol $\Psi$ stands for any element of the set of modality-symbols $\{\square, K, A, E, S, T, F, P, Z, G, W, O, B, U, Y\}$, then any object-language-expression of $\Sigma$ possessing the form $\Psi \alpha$, is a formula of $\Sigma$ as well. (Here, the meta-language-expression $\Psi \alpha$ is not a formula of $\Sigma$, but a scheme of formulae of $\Sigma$.)

6) Successions of symbols (belonging to the alphabet of the object-language of 
$\Sigma$ ) are formulae of $\Sigma$, if and only if this is so owing to the above-given items 1) -

5) of the present definition.

Now let us introduce the elements of the above-mentioned set of modality-symbols $\{\square, \mathrm{K}, \mathrm{A}, \mathrm{E}, \mathrm{S}, \mathrm{T}, \mathrm{F}, \mathrm{P}, \mathrm{Z}, \mathrm{G}, \mathrm{W}, \mathrm{O}, \mathrm{B}, \mathrm{U}, \mathrm{Y}\}$. Symbol $\square$ stands for the alethic modality "necessary". Symbols K, A, E, S, T, F, P, Z, respectively, stand for modalities "agent Knows that...", "agent A-priori knows that...", "agent Empirically (a-posteriori) knows that...", "under some conditions in some space-and-time a person (immediately or by means of some tools) Sensually perceives (has Sensual verification) that...", "it is True that...", "person has Faith (or believes) that...", "it is Provable that...", "there is an algorithm (a machine could be constructed) for deciding that...".

Symbols G, W, O, B, U, Y, respectively, stand for modalities "it is (morally) Good that...", "it is (morally) Wicked that...", "it is Obligatory that ...", "it is Beautiful that ...", "it is Useful that ...", "it is pleasant that ...". Meanings of the mentioned symbols are defined (indirectly) by the following schemes of own (proper) axioms of epistemology system $\Sigma$ which axioms are added to the axioms of classical propositional logic. Schemes of axioms and inference-rules of the classical propositional logic are applicable to all formulae of $\Sigma$.

Axiom scheme AX-1: A $\alpha \supset(\square \beta \supset \beta)$.

Axiom scheme AX-2: A $\alpha \supset(\square(\alpha \supset \beta) \supset(\square \alpha \supset \square \beta))$.

Axiom scheme AX-3: $\mathrm{A} \alpha \leftrightarrow(\mathrm{K} \alpha \&(\square \alpha \& \square \neg \mathrm{S} \alpha \& \square(\beta \leftrightarrow \Omega \beta)))$.

Axiom scheme AX-4: $\operatorname{E\alpha } \leftrightarrow(\operatorname{K} \alpha \&(\neg \square \alpha \vee \neg \square \neg \operatorname{S} \alpha \vee \neg \square(\beta \leftrightarrow \Omega \beta)))$

Axiom scheme AX-5: K $\alpha \supset \neg \square \neg \alpha$.

Axiom scheme AX-6: $(\square \beta \& \square \square \beta) \supset \beta$.

Axiom scheme AX-7: $\left(\mathrm{t}_{\mathrm{i}}=+=\mathrm{t}_{\mathrm{k}}\right) \leftrightarrow\left(\mathrm{G}\left[\mathrm{t}_{\mathrm{i}}\right] \leftrightarrow \mathrm{G}\left[\mathrm{t}_{\mathrm{k}}\right]\right)$.

Axiom scheme AX-8: $\left(\mathrm{t}_{\mathrm{i}}=+=\mathrm{g}\right) \supset \square \mathrm{G}\left[\mathrm{t}_{\mathrm{i}}\right]$.

Axiom scheme AX-9: $\left(\mathrm{t}_{\mathrm{i}}=+=\mathrm{b}\right) \supset \square \mathrm{W}\left[\mathrm{t}_{\mathrm{i}}\right]$.

Axiom scheme AX-10: (G $\supset \neg \mathrm{W} \alpha)$.

Axiom scheme AX-11: (W $\supset \neg \neg \alpha)$.

In AX-3 and AX-4, the symbol $\Omega$ (belonging to the meta-language) stands for any element of the set $\mathfrak{R}=\{\square, \mathrm{K}, \mathrm{T}, \mathrm{F}, \mathrm{P}, \mathrm{Z}, \mathrm{G}, \mathrm{O}, \mathrm{B}, \mathrm{U}, \mathrm{Y}\}$. Let elements of $\mathfrak{R}$ be called "perfection-modalities" or simply "perfections".

The axiom-schemes AX-10 and AX-11 are not new in evaluation logic: one can find them in the famous monograph by A. A. Ivin [61]. But the axiomschemes AX-7, AX-8, AX-9 are new ones representing not logic as such but formal axiology, i.e. abstract theory of forms of values in general ("formal logic" and "formal axiology" are not synonyms).

\section{A Precise Definition of Semantics of/for the Formal Theory $\Sigma$}

Meanings of the symbols belonging to the alphabet of object-language of $\Sigma$ owing to the items 1 - 3 of the above-given definition of the alphabet are defined by 
the classical propositional logic.

For defining semantics of specific aspects of object-language of formal theory $\Sigma$, it is necessary to define a set $\Delta$ (called "field of interpretation") and an interpreter called "valuator (evaluator)" $\mathrm{E}$.

In a standard interpretation of formal theory $\Sigma$, the set $\Delta$ (field of interpretation) is such a set, every element of which has: 1) one and only one axiological value from the set (good, bad\}; 2) one and only one ontological value from the set \{exists, not-exists\}.

The axiological variables $x, y, z$ range over (take their values from) the set $\Delta$.

The axiological constants "g" and "b" mean, respectively, "good" and "bad".

It is presumed here that axiological evaluating an element from the set $\Delta$, i.e. ascribing to this element an axiological value from the set \{good, bad\}, is performed by a quite definite (perfectly fixed) individual or collective valuator (evaluator) E. It is obvious that changing $\mathrm{E}$ can result in changing valuations of elements of $\Delta$. But laws of two-valued algebra of formal axiology do not depend upon changes of $\mathrm{E}$ as, by definition, formal-axiological laws of this algebra are such and only such constant evaluation-functions which obtain the value "good" independently from any changes of valuators. Thus, generally speaking, E is a variable which takes its values from the set of all possible evaluators (individual or collective-it does not matter). Nevertheless, a concrete interpretation of formal theory $\Sigma$ is necessarily fixing the value of $\mathrm{E}$; changing the value of the variable $\mathrm{E}$ is changing the concrete interpretation.

In a standard interpretation of formal theory $\Sigma$, ontological constants "e" and "n" mean, respectively, "exists" and "not-exists". Thus, in a standard interpretation of formal theory $\Sigma$, one and only one element of the set $\{\{g, e\},\{g, n\},\{b, e\}$, $\{\mathrm{b}, \mathrm{n}\}\}$ corresponds to every element of the set $\Delta$. The ontological constants " $\mathrm{e}$ " and " $n$ " belong to the meta-language. (According to the above-given definition of $\Sigma$ 's object-language-alphabet, "e" and " $n$ " do not belong to the objectlanguage.) But the ontological constants are indirectly represented at the level of object-language by square-bracketing. " $\mathrm{t}_{\mathrm{i}}$ exists" is represented by $\left[\mathrm{t}_{\mathrm{i}}\right]$; " $\mathrm{t}_{\mathrm{i}}$ not-exists" is represented by $\neg\left[\mathrm{t}_{\mathrm{i}}\right]$. Thus square-bracketing is a very important aspect of the system under investigation.

$N$-placed terms of $\Sigma$ are interpreted as $n$-ary algebraic operations (n-placed evaluation-functions) defined on the set $\Delta$. For instantiating the general notion "one-place evaluation-function" or "evaluation-function determined by one evaluation-argument" systematically used in two-valued algebra of formal axiology, see the above-given Table 1 and Table 2. For instantiating the general notion "evaluation-function determined by two evaluation-arguments" systematically exploited in two-valued algebra of formal axiology, see the above-given Table 3. (For correct understanding contents of this paper, it is worth emphasizing here that in the semantics of $\Sigma$, the symbols $F_{x}^{\mathrm{l}}, D^{\mathrm{l}} x W^{\mathrm{A}} x, U^{\mathrm{A}} x, P^{\mathrm{l}} x, W^{2} x y$, $E^{2} x y, T^{2} x y, P^{2} x y$ mean not predicates but terms. Being given an interpretation, the formulae $\left(\mathrm{t}_{\mathrm{i}}=+=\mathrm{t}_{\mathrm{k}}\right),\left(\mathrm{t}_{\mathrm{i}}=+=\mathrm{g}\right),\left(\mathrm{t}_{\mathrm{i}}=+=\mathrm{b}\right)$ are representations of predicates in $\Sigma$. 
If $t_{i}$ is a term of $\Sigma$, then, being interpreted, formula $\left[t_{i}\right]$ of $\Sigma$ is an either true or false proposition " $\mathrm{t}_{\mathrm{i}}$ exists". In a standard interpretation, formula $\left[\mathrm{t}_{\mathrm{i}}\right]$ is true if and only if $t_{i}$ has the ontological value "e (exists)" in that interpretation. The formula $\left[\mathrm{t}_{\mathrm{i}}\right]$ is a false proposition in a standard interpretation, if and only if $\mathrm{t}_{\mathrm{i}}$ has the ontological value "n (not-exists)" in that interpretation.

In a relevant interpretation, the formula $\left(t_{i}=+=t_{k}\right)$ of $\Sigma$ is translated into natural language by the proposition " $t_{i}$ is formally-axiologically equivalent to $t_{k}$ ", which proposition is true if and only if (in that interpretation) the terms $\left(t_{i}\right.$ and $t_{k}$ ) have identical axiological values from the set \{good, bad\} under any possible combination of axiological values of their axiological variables.

Now, having given exact definitions of all the significantly novel notions necessarily exploited for making and demonstrating the principal scientific discovery represented for the first time in this article, let us begin formal logical proving the theorem-scheme to be exploited necessarily as a tool (instrument) for obtaining the main result.

\section{A Formal Proof of $\left(A \alpha \supset\left(\left(t_{i}=+=t_{k}\right) \leftrightarrow\left(\left[t_{i}\right] \leftrightarrow\left[t_{k}\right]\right)\right)\right)$ in}

\section{the Formal Axiomatic Theory $\Sigma$}

The proof of theorem-scheme $\left(A \alpha \supset\left(\left(\mathrm{t}_{\mathrm{i}}=+=\mathrm{t}_{\mathrm{k}}\right) \leftrightarrow\left(\left[\mathrm{t}_{\mathrm{i}}\right] \leftrightarrow\left[\mathrm{t}_{\mathrm{k}}\right]\right)\right)\right)$ in $\Sigma$ is the following succession of formulae schemes.

1) $\mathrm{A} \alpha \leftrightarrow(\mathrm{K} \alpha \&(\square \alpha \& \square \neg \mathrm{S} \alpha \& \square(\beta \leftrightarrow \Omega \beta)))$ by axiom-scheme AX-3.

2) $\mathrm{A} \alpha \leftrightarrow\left(\operatorname{K} \alpha \&\left(\square \alpha \& \square \neg \mathrm{S} \alpha \& \square\left(\left[\mathrm{t}_{\mathrm{i}}\right] \leftrightarrow \mathrm{G}\left[\mathrm{t}_{\mathrm{i}}\right]\right)\right)\right)$ from 1 by substituting: $\mathrm{G}$ for $\Omega ;\left[\mathrm{t}_{\mathrm{i}}\right]$ for $\beta$.

3) A $\alpha \supset\left(\mathrm{K} \alpha \&\left(\square \alpha \& \square \neg \mathrm{S} \alpha \& \square\left(\left[\mathrm{t}_{\mathrm{i}}\right] \leftrightarrow \mathrm{G}\left[\mathrm{t}_{\mathrm{i}}\right]\right)\right)\right)$ from 2 by the rule of $\leftrightarrow$ elimination.

4) Aa assumption.

5) $\mathrm{K} \alpha \&\left(\square \alpha \& \square \neg \mathrm{S} \alpha \& \square\left(\left[\mathrm{t}_{\mathrm{i}}\right] \leftrightarrow \mathrm{G}\left[\mathrm{t}_{\mathrm{i}}\right]\right)\right)$ from 3 and 4 by modus ponens.

6) $\square\left(\left[\mathrm{t}_{\mathrm{i}}\right] \leftrightarrow \mathrm{G}\left[\mathrm{t}_{\mathrm{i}}\right]\right)$ from 5 by the rule of eliminating \&.

7) $\left(\left[\mathrm{t}_{\mathrm{i}}\right] \leftrightarrow \mathrm{G}\left[\mathrm{t}_{\mathrm{i}}\right]\right)$ from 4 and 6 by a rule of $\square$ elimination. (The rule of elimination is derivative rule ${ }^{1}$ in $\Sigma$.)

8) $\mathrm{A} \alpha \leftrightarrow\left(\mathrm{K} \alpha \&\left(\square \alpha \& \square \neg \mathrm{S} \alpha \& \square\left(\left[\mathrm{t}_{\mathrm{k}}\right] \leftrightarrow \mathrm{G}\left[\mathrm{t}_{\mathrm{k}}\right]\right)\right)\right)$ from 1 by substituting: $\mathrm{G}$ for $\Omega$; $\left[\mathrm{t}_{\mathrm{k}}\right]$ for $\beta$.

9) $\mathrm{A} \alpha \supset\left(\mathrm{K} \alpha \&\left(\square \alpha \& \square \neg \mathrm{S} \alpha \& \square\left(\left[\mathrm{t}_{\mathrm{k}}\right] \leftrightarrow \mathrm{G}\left[\mathrm{t}_{\mathrm{k}}\right]\right)\right)\right)$ from 8 by the rule of eliminating $\leftrightarrow$.

10) $\mathrm{K} \alpha \&\left(\square \alpha \& \square \neg \mathrm{S} \alpha \& \square\left(\left[\mathrm{t}_{\mathrm{k}}\right] \leftrightarrow \mathrm{G}\left[\mathrm{t}_{\mathrm{k}}\right]\right)\right)$ from 4 and 9 by modus ponens.

11) $\square\left(\left[\mathrm{t}_{\mathrm{k}}\right] \leftrightarrow \mathrm{G}\left[\mathrm{t}_{\mathrm{k}}\right]\right)$ from 10 by the rule of eliminating \&.

12) $\left(\left[\mathrm{t}_{\mathrm{k}}\right] \leftrightarrow \mathrm{G}\left[\mathrm{t}_{\mathrm{k}}\right]\right)$ from 4 and 11 by the rule of $\square$ elimination.

${ }^{1}$ The derivative rule of $\square$ elimination is formulated as follows: $A \alpha, \square \beta \vdash \beta$. This rule is not included into the above-given definition of $\Sigma$, but it is easily derivable in $\Sigma$ by means of the axiom scheme AX-1 and modus ponens. (The rule $\square \beta \vdash \beta$ is not derivable in $\Sigma$, and also Gödel's necessitation rule is not derivable in $\Sigma$. Nevertheless, a limited or conditioned necessitation rule is derivable in $\Sigma$, namely, $\quad A \alpha, \beta \vdash \square \beta$.) 
13) $\left(\mathrm{t}_{\mathrm{i}}=+=\mathrm{t}_{\mathrm{k}}\right) \leftrightarrow\left(\mathrm{G}\left[\mathrm{t}_{\mathrm{i}}\right] \leftrightarrow \mathrm{G}\left[\mathrm{t}_{\mathrm{k}}\right]\right)$ axiom-scheme AX-7.

14) $\left(t_{i}=+=t_{k}\right) \supset\left(G\left[t_{i}\right] \leftrightarrow G\left[t_{k}\right]\right)$ from 13 by the rule of $\leftrightarrow$ elimination.

15) $\left(\mathrm{t}_{\mathrm{i}}=+=\mathrm{t}_{\mathrm{k}}\right)$ assumption.

16) $\left(\mathrm{G}\left[\mathrm{t}_{\mathrm{i}}\right] \leftrightarrow \mathrm{G}\left[\mathrm{t}_{\mathrm{k}}\right]\right)$ from 14 and 15 by modus ponens.

17) $\left(\left[t_{i}\right] \leftrightarrow G\left[t_{k}\right]\right)$ from 7 and 16 by the rule of transitivity of $\leftrightarrow$.

18) $\left(G\left[t_{k}\right] \leftrightarrow\left[t_{k}\right]\right)$ from 12 by the rule of commutativity of $\leftrightarrow$.

19) $\left(\left[t_{i}\right] \leftrightarrow\left[t_{k}\right]\right)$ from 17 and 18 by the rule of transitivity of $\leftrightarrow$.

20) $A \alpha,\left(t_{i}=+=t_{k}\right) \vdash\left(\left[t_{i}\right] \leftrightarrow\left[t_{k}\right]\right)$ by the succession $1-19$.

21) $A \alpha \vdash\left(t_{i}=+=t_{k}\right) \supset\left(\left[t_{i}\right] \leftrightarrow\left[t_{k}\right]\right)$ from 20 by the rule of $\supset$ introduction.

22) $\left(G\left[t_{i}\right] \leftrightarrow G\left[t_{k}\right]\right) \supset\left(t_{i}=+=t_{k}\right)$ from 13 by the rule of $\leftrightarrow$ elimination.

23) $\left(\left[\mathrm{t}_{\mathrm{i}}\right] \leftrightarrow\left[\mathrm{t}_{\mathrm{k}}\right]\right)$ assumption.

24) $\left(\mathrm{G}\left[\mathrm{t}_{\mathrm{i}}\right] \leftrightarrow\left[\mathrm{t}_{\mathrm{i}}\right]\right)$ from 7 by the rule of commutativity of $\leftrightarrow$.

25) $\left(\mathrm{G}\left[\mathrm{t}_{\mathrm{i}}\right] \leftrightarrow \mathrm{G}\left[\mathrm{t}_{\mathrm{k}}\right]\right)$ from 24 and 17 by the rule of transitivity of $\leftrightarrow$.

26) $\left(t_{i}=+=t_{k}\right)$ from 22 and 25 by modus ponens.

27) $A \alpha,\left(\left[t_{i}\right] \leftrightarrow\left[t_{k}\right]\right) \vdash\left(t_{i}=+=t_{k}\right)$ by the succession $1-26$.

28) $\mathrm{A} \alpha \vdash\left(\left[\mathrm{t}_{\mathrm{i}}\right] \leftrightarrow\left[\mathrm{t}_{\mathrm{k}}\right]\right) \supset\left(\mathrm{t}_{\mathrm{i}}=+=\mathrm{t}_{\mathrm{k}}\right)$ from 27 by the rule of $\supset$ introduction.

29) $A \alpha \vdash\left(\left(t_{i}=+=t_{k}\right) \leftrightarrow\left(\left[t_{i}\right] \leftrightarrow\left[t_{k}\right]\right)\right)$ from 28 and 21 by the rule of $\leftrightarrow$ introduction.

30) $\vdash \mathrm{A} \alpha \supset\left(\left(\mathrm{t}_{\mathrm{i}}=+=\mathrm{t}_{\mathrm{k}}\right) \leftrightarrow\left(\left[\mathrm{t}_{\mathrm{i}}\right] \leftrightarrow\left[\mathrm{t}_{\mathrm{k}}\right]\right)\right)$ from 29 by the rule of $\supset$ introduction.

Here we are! Originally, this proof had been published in [57] and then repeated in [51] [52].

\section{Formal Logical Inferring the Energy-Conservation Law of Proper Physics in the Formal Theory Sigma from Conjunction of the Assumption of Knowledge A-Priori-Ness and the Formal-Axiological Analog of the Indicated Law of Physics}

By means of the theorem-scheme proved above in paragraph 6 of the present article, from conjunction of (I) the formal-axiological equivalence 22 belonging to the list of equations proved above in paragraph 3 , and (II) the assumption that $\mathrm{A} \alpha$, the equivalence $\left(\left[I^{1} x\right] \leftrightarrow\left[C^{1} F^{1} K^{1} E^{1} x\right]\right)$ is formally logically derivable within the formal axiomatic theory Sigma. Here it is worth highlighting that $\left(\left[I^{1} x\right] \leftrightarrow\left[C^{1} F^{1} K^{1} E^{1} x\right]\right)$ is the equivalence of statements of being.

Thus, owing to the above-proved theorem-scheme, with respect to Sigma, it is true that: A $\alpha,\left(I^{1} x=+=C^{1} F^{1} K^{1} E^{1} x\right) \vdash\left(\left[I^{1} x\right] \leftrightarrow\left[C^{1} F^{1} K^{1} E^{1} x\right]\right)$, where “... $\vdash$ " means "from ... it is logically derivable (in Sigma) that...". In other words, according to the above-said, if knowledge is pure a-priori one, then there is a formal proof in $\Sigma$ for the law of conservation of energy in proper physics. Thus, within a system of pure a priori knowledge of nature-laws logically organized by the theory $\Sigma$, the great law of conservation of finite quantity of energy in any closed (isolated) system $x$ is strictly provable; namely, conservation (constant-ness, immutability) of a finite quantity of energy of $x$ exists if and only if it 
is true that $x$ is perfectly isolated (closed).

The above discourse of the great law of conservation of energy has been a complicated entanglement (intertwinement) of ontology, epistemology and axiology; the epistemological relationship between "is" and "is good" has been considered. But, generally speaking, couples "being"; "being good" and "being"; "being prescribed" are not identical, because, in general, goodness and obligatoriness are not synonyms. The notions "good" and "bad" are studied by axiology (general theory of value) and evaluation logic [61], while the notions "prescribed (commanded)", "obligatory", "prohibited", "permitted" are studied by deontology (general theory of duty) and deontic logic, or logic of norms [62]. To fill in the blank, let us consider the deontic (normative) aspect of the great law of conservation, although the invitation to do this seems, at least, very strange (if not a result of "metaphysical intoxication of mind"). However, the evidently odd discourse of a deontic (normative) aspect of pure a-priori laws of physics is not completely my own invention; in this relation I follow the precedent made by I. Kant [63] [64] [65].

\section{Kant's Paradoxical Statement of Physicist's Prescribing Pure A-Priori Laws to Nature (Is the Great Law of Conservation Prescribed?)}

Among specialists in history of philosophical grounding physics, it is well-known that I. Kant has affirmed that pure a-priori laws of physics are prescribed to nature by physicist's understanding. At first glance, such affirming seems very strange. As a rule, the physicists who deal exclusively with experiments, facts and measurements, believe not in physicist mind's prescribing laws to nature but in nature's prescribing laws to physicist's mind. Usually, the contrary position is evaluated by the physicists as a vulgar (or "subjective") idealism which is labeled by them as utterly not sound philosophical worldview incompatible with proper science of nature. I. Kant used to criticize the vulgar (or "psychological") idealism as well [63] [64]. Nevertheless, he insisted that physicist's understanding prescribes pure a-priori laws to nature [63] [64] [65]. However, some people refuse to believe that the sage of Königsberg does have affirmed and even does have written such an absurd in his printed works on philosophy of physics. Usually, the nonbelievers require to submit relevant citations from Kant's own writings. Therefore, let us submit here the required citations:

"It has hitherto been assumed that our cognition must conform to the objects; but all attempts to ascertain anything about these objects a priori, by means of conceptions, and thus to extend the range of our knowledge, have been rendered abortive by this assumption. Let us then make an experiment whether we may not be more successful in metaphysics, if we assume that the objects must conform to our cognition" ([63], p. 7).

$* * *$

"Even the main proposition that has been elaborated throughout this entire 
part, already leads by itself to the proposition: that the highest legislation for nature must lie in our self, i.e., in our understanding, and that we must not seek the universal laws of nature from nature by means of experience, but, conversely, must seek nature, as regards its universal conformity to law, solely in the conditions of the possibility of experience that lie in our sensibility and understanding; ..." ([65], p. 71).

$* * *$

"We must, however, distinguish empirical laws of nature, which always presuppose particular perceptions, from the pure or universal laws of nature, which, without having particular perceptions underlying them, contain merely the conditions for the necessary unification of such perceptions in one experience; with respect to the latter laws, nature and possible experience are one and the same, and since in possible experience the lawfulness rests on the necessary connection of appearances in one experience (without which we would not be able to cognize any object of the sensible world at all), and soon the original laws of the understanding, then, even though it sounds strange at first, it is nonetheless certain, if I say with respect to the universal laws of nature: the understanding does not draw its (a priori) laws from nature, but prescribes them to it' ([65], p. 71-72).

Those who do not believe that Kant does have formulated such odd statement himself, think that this queer statement makes a significant discrepancy (even inconsistency) in Kant's philosophy of physics. Below in the present article, at the level of the discrete mathematical model, I am to demonstrate that the impression of Kant's self-contradiction is an illusion naturally arising from complete identifying notions: "knowledge (in general)", "a-priori-knowledge", and "a-posteriori-knowledge". Such identifying is a blunder to be eliminated ${ }^{2}$. However, being psychologically camouflaged the blunder is committed by negligence very often. Therefore, in first approximation, Kant's extraordinary idea of physicist's prescribing a-priori laws to nature seems somewhat paradoxical and enigmatic. The puzzling idea has attracted special attention by respectable researchers: M. Massimi [66] [67]; M. Massimi and A. Breitenbach [68]; K. Pollok [69]; E. Watkins [70]. In complement to these publications systematically studying Kant's works (written in natural language) by methods of history of philosophy, below in this paper for the first time in philosophy of physics and in Kantian studies, a significantly new interpretation, explication, and reconstruction of Kant's enigmatic idea is undertaken by means of a formal axiomatic epistemology theory $\Sigma$ formulated in an unambiguous artificial language.

In the logically formalized axiomatic theory $\Sigma$, the formula-scheme $(\mathrm{A} \alpha \supset(\square \beta \leftrightarrow \mathrm{O} \beta))$ is a scheme of theorems. Here: symbols $\alpha$ and $\beta$ stand for any formulae of $\Sigma$; Aa stands for "person (physicist) a-priori knows that $\alpha$ ";

${ }^{2}$ Deliberate logical separating and synthesizing consistently the three significantly different notions: "knowledge (in general)"; "a-priori knowledge"; and "empirical knowledge" is realized by means of the above-defined formal axiomatic epistemology theory $\Sigma$. 
$\square \beta$ stands for "it is necessary that $\beta$ ", and $O \beta$ stands for "it is commanded, prescribed, obligatory that $\beta$ ". The modality $\square \beta$ represents a law of nature. The modality $\mathrm{O} \beta$ represents "physicist's command, prescription, making obligatory that $\beta$ ". The theorem-scheme $(A \alpha \supset(\square \beta \leftrightarrow O \beta))$ formally proved (within $\Sigma$ ) below in this article is considered as a discrete mathematical model of/for the enigmatic statement by Kant. To convince the nonbelievers, first of all, let us prove a more general theorem-scheme $(A \alpha \supset(\Theta \beta \leftrightarrow \mathrm{O} \beta))$, where the symbols $\Theta$ and $\Omega$ (belonging to the meta-language) stand for any elements of the set of perfection-modalities $\Re=\{\square, K, T, F, P, Z, G, O, B, U, Y\}$. A formal proof of the theorem-scheme $(A \alpha \supset(\Theta \beta \leftrightarrow \mathrm{O} \beta))$ in $\Sigma$ is the following succession 1 11 of formula-schemes. A formal proof of the theorem-scheme $(\mathrm{A} \alpha \supset(\square \beta \leftrightarrow \mathrm{O} \beta))$ in $\Sigma$ is the following succession 1-13 of formula-schemes.

1) $\mathrm{A} \alpha \leftrightarrow(\mathrm{K} \alpha \&(\square \alpha \& \square \neg \mathrm{S} \alpha \& \square(\beta \leftrightarrow \Omega \beta)))$ : axiom scheme AX-3.

2) $\mathrm{A} \alpha \supset(\operatorname{K} \alpha \&(\square \alpha \& \square \neg \mathrm{S} \alpha \& \square(\beta \leftrightarrow \Omega \beta)))$ : from 1 by the rule of elimination of $\leftrightarrow$.

3) Aa: assumption.

4) $(\operatorname{K} \alpha \&(\square \alpha \& \square \neg \operatorname{S} \alpha \& \square(\beta \leftrightarrow \Omega \beta)))$ : from 2 and 3 by modus ponens.

5) $\square(\beta \leftrightarrow \Omega \beta)$ : from 4 by the rule of elimination of $\&$.

6) $(\beta \leftrightarrow \Omega \beta)$ : from 5 and 3 by the derivative rule of elimination of $\square$.

7) $(\beta \leftrightarrow \Theta \beta)$ : from 6 by substituting $\Theta$ for $\Omega$.

8) $(\Theta \beta \leftrightarrow \beta)$ : from 7 by commutativity of $\leftrightarrow$.

9) $(\Theta \beta \leftrightarrow \Omega \beta)$ : from 8 and 6 by transitivity of $\leftrightarrow$.

10) $\mathrm{A} \alpha \vdash(\Theta \beta \leftrightarrow \Omega \beta)$ : by 1 - 9. (The symbol “... ..." stands for "from...it is logically derivable in $\Sigma$ that...”.)

11) $\vdash \mathrm{A} \alpha \supset(\Theta \beta \leftrightarrow \Omega \beta)$ : from 10 by the rule of introduction of $\supset$.

12) $\vdash \mathrm{A} \alpha \supset(\mathrm{G} \beta \leftrightarrow \square \beta)$ : from 11 by substituting $\mathrm{G}$ for $\Theta ; \square$ for $\Omega$.

13) $\vdash \mathrm{A} \alpha \supset(\square \beta \leftrightarrow \mathrm{O} \beta)$ : from 11 by substituting $\square$ for $\Theta$; O for $\Omega$.

14) $\vdash \mathrm{A} \alpha \supset(\mathrm{G} \beta \leftrightarrow \mathrm{O} \beta)$ : from 11 by substituting $\mathrm{G}$ for $\Theta$; O for $\Omega$.

Here we are!

In my opinion, the triple of elements 12), 13), 14) of this succession of formula-schemes justifies the odd Kant statement successfully. Now let us consider another option of justifying the queer Kant statement, namely, let us examine and discuss the following formal-proof scheme.

1) $\mathrm{A} \alpha \leftrightarrow(\mathrm{K} \alpha \&(\square \alpha \& \square \neg \mathrm{S} \alpha \& \square(\beta \leftrightarrow \Omega \beta)))$ : axiom scheme AX-3.

2) $\mathrm{A} \alpha \leftrightarrow(\operatorname{K} \alpha \&(\square \alpha \& \square \neg \operatorname{S} \alpha \& \square(\alpha \leftrightarrow \Omega \alpha)))$ : from 1 by substituting $\alpha$ for $\beta$.

3) $\mathrm{A} \alpha \supset(\operatorname{K} \alpha \&(\square \alpha \& \square \neg \mathrm{S} \alpha \& \square(\alpha \leftrightarrow \Omega \alpha)))$ : from 1 by the rule of elimination of $\leftrightarrow$.

4) Aa: assumption.

5) $(\mathrm{K} \alpha \&(\square \alpha \& \square \neg \mathrm{S} \alpha \& \square(\alpha \leftrightarrow \Omega \alpha)))$ : from 2 and 3 by modus ponens.

6) $\square(\alpha \leftrightarrow \Omega \alpha)$ : from 5 by the rule of elimination of $\&$.

7) $(\alpha \leftrightarrow \Omega \alpha)$ : from 6 and 4 by the derivative rule of $\square$ elimination.

8) $(\alpha \supset \Omega \alpha)$ : from 7 by the rule of elimination of $\leftrightarrow$. 
9) $\square \alpha$ : from 5 by the rule of elimination of \&.

10) a: from 9 and 4 by the derivative rule of $\square$ elimination.

11) $\Omega \alpha$ : from 8 and 10 by modus ponens.

12) $\mathrm{A} \alpha \vdash \Omega \alpha$ : by $1-9$.

13) $\vdash($ A $\alpha \supset \Omega \alpha)$ : from 12 by the rule of introduction of $\supset$.

14) $\mathrm{A} \alpha \vdash \mathrm{O} \alpha$ : from 12 by substituting $\mathrm{O}$ for $\Omega$.

15) $\vdash(\mathrm{A} \alpha \supset \mathrm{O} \alpha)$ : from 14 by the rule of introduction of $\supset$.

According to the items 14 and 15 of this succession of formula-schemes, Kant's statement in question is justified in general; the sage of Konigsberg is vindicated. If one's knowledge of the law of conservation of energy in physics is pure a-priori, then the enigmatic statement by Kant is exemplified: our understanding prescribes the pure a-priori law of conservation of energy to nature.

Although in modal logics, $\square q$, O $q, \mathrm{G} q$ (and, in general, $\Omega q$ ) do not have truth-functional meanings, in two-valued algebraic system of formal axiology the mentioned modalities have abstract-value-functional meanings, namely, either "g (good)" or "b (bad)" [10] [24] [25] [26] [53], which meanings are formal-axiological ones. This is so because formal logic and formal axiology do not coincide: "truth" and "good (as abstract positive value in general)" are not synonyms. In spite of B. Russel [44], absolute good (formal-axiological law) does exist (in two-valued algebra of formal axiology): the domain of perfectly rational relativism in axiology is reduced to empirical knowledge exclusively; beyond this domain the relativism becomes irrational. The exact border-line of the domain of perfectly rational relativism in axiology is established by the two: (I) algebra of formal axiology defined precisely above in paragraph 2 of this paper, and (II) the logically formalized axiomatic epistemology-and-axiology theory $\Sigma$ precisely formulated above in paragraphs 4 and 5 of this paper.

According to the wonderful theorem-scheme $\left(A \alpha \supset\left(\left(\mathrm{t}_{\mathrm{i}}=+=\mathrm{t}_{\mathrm{k}}\right) \leftrightarrow\left(\left[\mathrm{t}_{\mathrm{i}}\right] \leftrightarrow\left[\mathrm{t}_{\mathrm{k}}\right]\right)\right)\right)$, a formal proof of which is given above in this paper (in paragraph 6), in spite of D. Hume [71] [72] and G.E. Moore [73], the logically unbridgeable gap between statements of being and statements of value exists not unlimitedly, but only within the realm of empirical knowledge. If and only if discourse is accomplished within the realm of pure a-priori knowledge, the gap in question is logically bridgeable [51] [52] [57]. Due to this extraordinary logical bridge (or a "logical mole-hole"), above in this paper the law of conservation of energy has been derived logically from its formal-axiological analog (formal-axiological Equation (22) in paragraph 3 of this paper) in the logically formalized axiomatic epistemology-and-axiology theory $\Sigma$, under the presumption (condition) that knowledge is pure a-priori.

The wonderful theorem-schemes $(A \alpha \supset(\Theta \beta \leftrightarrow \Omega \beta))$ and $(A \alpha \supset \Omega \alpha)$ and their psychologically surprising logical consequences $(A \alpha \supset(\square \beta \leftrightarrow \mathrm{O} \beta))$ and $(\mathrm{A} \alpha \supset \mathrm{O} \alpha)$ are formally proved above within $\Sigma$ (in the present paragraph of this paper). According to these wonderful logical consequences, in spite of G.H. von Wright [74] [75] [76], the domain of perfectly rational rejecting the 
equivalence $(\square \beta \leftrightarrow \mathrm{O} \beta)$ is reduced to empirical knowledge exclusively; beyond this domain, namely, in sphere of pure a-priori knowledge the rejection is wrong [58] [59] [60]. Moreover, by means of the extraordinary theoremschemes $(A \alpha \supset(\square \beta \leftrightarrow O \beta))$ and $(A \alpha \supset \Omega \alpha)$, I. Kant's psychologically surprising statement that physicist's understanding prescribes the pure a-priori laws to nature, is explicated, explained, demonstrated, and vindicated. Existence of the negative attitude to Kant's statement under discussion is explained as a result of irrelevant using his statement beyond the limited sphere of its perfect rationality. The domain of perfect rationality of the psychologically surprising statement by Kant is reduced to pure a-priori knowledge exclusively; beyond this extraordinary domain, the queer statement by Kant becomes irrational, certainly, in sphere of empirical knowledge it is wrong. Nevertheless, according to the present article, there is a very small but not-empty extraordinary realm (a "logical mole-hole") in which Kant's statement in question is true necessarily.

\section{Conclusion}

Thus, for the first time in relevant literature, the physical law of conservation of energy is formally deductively inferred, in the logically formalized epistemology-and-axiology theory Sigma, from conjunction of (a) a formal-axiological analog of the physical law in two-valued algebraic system of metaphysics as formal axiology, and (b) the assumption of a-priori-ness of knowledge. The original formal deductive inference of the physical law of conservation of energy from the indicated premises within the formal theory Sigma is the main new nontrivial scientific result of this paper not published elsewhere. Another new nontrivial scientific result published in this article is formal deductive demonstrating Kant's surprising statement that physicist prescribes pure a-priori laws to nature, in general, and, consequently, if knowledge of the law of conservation of energy is pure a-priori one, then it is prescribed to nature by physicist's understanding. Hitherto this Kant's puzzling statement has been discussed by means of natural language exclusively. At the level of artificial language, the formal deductive demonstration of the nontrivial statement in question by means of the formal theory Sigma is presented in this article first-ever.

\section{Conflicts of Interest}

The author declares no conflicts of interest regarding the publication of this paper.

\section{References}

[1] Dircks, H. (1870) Perpetuum Mobile; or, a History of the Search for Self-Motive Power from the 13th to the 19th Century. W. Clowers \& Sons, London.

[2] Mach, E. (1911) History and Root of the Principle of the Conservation of Energy. The Open Court, Chicago.

[3] Poincaré, H. (1994) Science and Hypothesis. In: Adler, M.J., Ed., Great Books of the 
Western World, Vol. 56, 20 th Century Natural Science, Encyclopedia Britannica, Inc., Chicago, 1-70.

[4] Sarton, G., Mayer, J.R., Joule, J.P. and Carnot, S. (1929) The Discovery of the Law of Conservation of Energy. Isis, 13, 18-49. https://doi.org/10.1086/346430

[5] Kuhn, T.S. (1959) Energy Conservation as an Example of Simultaneous Discovery. In: Clagett, M., Ed., Critical Problems in the History of Science, University of Wisconsin Press, Madison, 321-356.

[6] Elkana, Y. (1974) The Discovery of the Conservation of Energy. Harvard University Press, Cambridge.

[7] Wisniak, J. (2008) Conservation of Energy. Readings on the Origins of the First Law of Thermodynamics. Part I. Educación Quimica, 19, 159-171. https://doi.org/10.22201/fq.18708404e.2008.2.25806

[8] Wisniak, J. (2008) Conservation of Energy. Readings on the Origins of the First Law of Thermodynamics. Part II. Educación Quimica, 19, 216-225. https://doi.org/10.22201/fq.18708404e.2008.3.25835

[9] Aristotle (1994) The Works of Aristotle. V.I. In: Adler, M.J., Ed., Great Books of the Western World, Vol. 7, Encyclopedia Britannica, Inc., Chicago, 1-726.

[10] Lobovikov, V.O. (2007) Mathematical Ethics, Metaphysics, and the Natural Law (Algebra of Metaphysics as Algebra of Formal Axiology) [Matematicheskaya etika, metafizika i estestvennoe pravo (Algebra metafiziki kak algebra formal noi aksiologii)]. Ekaterinburg: Institut filosofii i prava Ural skogo otdeleniya Rossiiskoi akademii nauk. (In Russian)

[11] Lobovikov, V.O. (2012) Eleates' Metaphysical Doctrine of Movement (Parmenides, Melissus) and Physics Law of Conservation of Energy, from the Viewpoint of Two-Valued Algebra of Metaphysics as Formal Axiology. In: Konverskiy, A.E., Ed., Science Days of the Department of Philosophy-2012, Proceedings of the International Scientific Conference, Publishing Center "Kiev University", Kiev, Part 6, 113-114.

[12] Lobovikov, V.O. (2012) From the Finitism in Mathematics to a Finitism in Physics. Philosophy of Science [Filosofiya nauki], 4, 36-48. (In Russian)

[13] Lobovikov, V.O. (2015) A Principle of Finitism in Nature-Philosophy and the Great Laws of Conservation in the Light of Two-Valued Algebra of Metaphysics as Formal Axiology (Physics of Parmenides and Melissus, and Its Value-Functional Connection with the Laws of Conservation of Energy and of Electric Charge). Journal of Tomsk State University. Series: Philosophy, Sociology, Political Studies, 30, 29-38. https://doi.org/10.17223/1998863X/30/4

[14] Lobovikov, V.O. (2015) Formal Defining the Domain of Applicability of "Hume Guillotine" and Explicating the Border-Line between Metaphysics of Nature and the Classical Physics by Means of Two-Valued Algebra of Metaphysics as Formal Axiology). Journal of Tomsk State University. Series. Philosophy, Sociology, Political Studies, 32, 115-124. https://doi.org/10.17223/1998863X/32/13

[15] Hilbert, D. (1967) On the Infinite. In: Van Heijenoort, J., Ed., From Frege to Gödel. A Source Book in Mathematical Logic, 1897-1931, Harvard University Press, Cambridge, 367-392.

[16] Hilbert, D. (1990) Foundations of Geometry [Grundlagen der Geometrie]. Translated by Unger, Leo, 2nd English Edition, Open Court Publishing Co., La Salle.

[17] Hilbert, D. (1996) Axiomatic Thought. In: Ewald, W.B., Ed., From Kant to Hilbert. A Source Book in the Foundations of Mathematics, Vol. 2, Oxford University Press Inc., Oxford, New York, 1105-1115. 
[18] Hilbert, D. (1996) The New Grounding of Mathematics: First Report. In: Ewald, W.B., Ed., From Kant to Hilbert: A Source Book in the Foundations of Mathematics, Vol. 2, Oxford University Press Inc., Oxford, New York, 1115-1134.

[19] Hilbert, D. (1996) The Logical Foundations of Mathematics. In: Ewald, W.B., Ed., From Kant to Hilbert. A Source Book in the Foundations of Mathematics, Vol. 2, Oxford University Press Inc., Oxford, New York, 1134-1147.

[20] Hilbert, D. (1996) Logic and the Knowledge of Nature. In: Ewald, W.B., Ed., From Kant to Hilbert. A Source Book in the Foundations of Mathematics, Vol. 2, Oxford University Press Inc., Oxford, New York, 1157-1165.

[21] Wittgenstein, L. (1992) Tractatuslogico-philosophicus. Routledge \& K. Paul, London, New York.

[22] Lobovikov, V.O. (1980) An Algebraization of Some Fragments of Ethics as a Prerequisite of Their Formalization [Algebraizatsiya otdel'nykh fragmentov etiki kak predposylka ikh formalizatsii]. The Conference "Problems and Vistas of Using Logic-Cybernetic Technics" [ Tezisy konferentsii "Problemy i perspektivy ispol zovaniya logiko-kiberneticheskoi tekhniki”], Oblastnoisovet NTO, Sverdlovsk, 49-51. (In Russian)

[23] Lobovikov, V.O. (1984) A New Not-Logic Interpretation of Mathematical Apparatus of the Classical First-Order Predicate Logic [Novaya nelogicheskaya interpretatsiya matematicheskogo apparata klassicheskoi logiki predikatov pervogo poryadka]. In: Logic, Cognition, Reflection [Logika, poznanie, otrazhenie], Ural University Press, Sverdlovsk, 33-58. (In Russian)

[24] Lobovikov, V.O. (1984) Modal Logic of Evaluations and of Norms from the Viewpoint of Content Ethics and Law [Modal'naya logika ocenok i norm s tochki zreniya soderzhatel'noj etiki i prava]. Krasnoyarsk University Press, Krasnoyarsk. (In Russian)

[25] Lobovikov, V.O. (2007) Aristotelian and Juridical Modalities: A New Theory of Their Unity (A Two-Valued Algebra of Formal Natural-Law Philosophy of Modalities as Moral-Legal Evaluation-Functions Determined by Two Variables-A Complement to G. H. Wright's Deontic Logic Interpretation of G. W. Leibniz's Idea about the Unity of the Two Kinds of Modalities). Brazilian Legal Theory Review RFDCL, 3, 181-187.

[26] Lobovikov, V.O. (2011) Discrete Mathematical Representing G. W. Leibniz' Philosophy of Law, Morals and Theology by Means of Two-Valued Algebra of the Natural Law (Studying Moral-Legal Evaluation-Functions Determined by Two Variables in Algebra of Formal Axiology). In: Breger, H., Herbst, J. and Erdner, S., Eds., XI International Leibniz-Congress "Nature and Subject" under the Auspices of Federal President, Vol. 2, AkademieVerlag; Bahlsen GmbH \& Co. KG, Berlin, 611-615.

[27] Lobovikov, V. (2009) The Finitism by D. Hilbert, the "Naïve Finitism" by L. Kronecker, and the Metaphysics by Eleates (Parmenides and Melissus), from the Viewpoint of Two-Valued Algebra of Formal Ethics [Finitizm D. Gil'berta, naivnyjfinitizm L. Kronekera i metafizikaeleatov (Parmenida i Melissa) s tochki zreniya dvuznachnoj algebry formal'noj etiki]. Philosophy of Science [Filosofiya nauki], 43, 34-46. (In Russian)

[28] Mach, E. (1914) The Analysis of Sensations, and the Relation of the Physical to the Psychical. Open Court, Chicago. https://doi.org/10.2307/3604840

[29] Mach, E. (1919) The Science of Mechanics. A Critical and Historical Account of Its Development. Open Court, Chicago. 
[30] Mach, E. (2006) Measurement and Representation of Sensations. L. Eribaum Associates, Mahwah.

[31] Carnap, R. (1931) Overcoming Metaphysics by Logical Analysis of Language [Überwindung der MetaphysikdurchlogischeAnalyse der Sprache]. Erkenntnis, 2, 219-241. https://doi.org/10.1007/BF02028153

[32] Carnap, R. (1935) The Rejection of Metaphysics. In: Weitz, M., Ed., 20 th Century Philosophy: The Analytic Tradition, Free Press, New York, 206-220.

[33] Carnap, R. (1956) Meaning and Necessity: A Study in Semantics and Modal Logic. University of Chicago Press, Chicago and London.

[34] Carnap, R. (1967) The Logical Structure of the World. Pseudo-Problems in Philosophy. University of California Press, Berkeley and Los Angeles.

[35] Schlick, M. (1974) General Theory of Knowledge. Springer-Verlag, Wien. https://doi.org/10.1007/978-3-7091-3099-5

[36] Schlick, M. (1979) Philosophical Papers (Volume I). D. Reidel, Dordrecht.

[37] Schlick, M. (1979) Philosophical Papers (Volume II). D. Reidel, Dordrecht.

[38] Ayer, A.J. (1952) Language, Truth and Logic. Dover Publications, New York.

[39] Ayer, A.J. (1954) Philosophical Essays. Mcmillan, London.

[40] Ayer, A.J. (1959) Logical Positivism. The Free Press, New York.

[41] Russell, B. (1914) On Scientific Method in Philosophy. Clarendon Press, Oxford.

[42] Russell, B. (1948) Human Knowledge: Its Scope and Limits. George Allen and Unwin, London; Simon and Schuster, New York.

[43] Russell, B. (1956) Logic and Knowledge. George Allen and Unwin, London.

[44] Russell, B. (1986) Is There an Absolute Good? Russel: The Journal of Bertrand Russell Studies, 6, 144-149. https://doi.org/10.15173/russell.v6i2.1679

[45] Russell, B. (1992) An Inquiry into Meaning and Truth. Routledge, London.

[46] Whitehead, A.N. (1941) Mathematics and the Good. In: Schilpp, P.A., Ed., The Philosophy of Alfred North Whitehead [The Library of Living Philosophers, Vol. 3], Northwestern University Press, Evanston and Chicago, 666-681.

[47] Byers, N. (1998) E. Noether's Discovery of the Deep Connection between Symmetries and Conservation Laws.

[48] Kosmann-Schwarzbach, Y. (2011) The Noether Theorems. Invariance and Conservation Laws in the Twentieth Century. Sources and Studies in the History of Mathematics and Physical Sciences. Springer, New York. https://doi.org/10.1007/978-0-387-87868-3

[49] Hanca, J., Tulejab, S. and Hancova, M. (2004) Symmetries and Conservation Laws: Consequences of Noether's Theorem. American Journal of Physics, 72, 428-435. https://doi.org/10.1119/1.1591764

[50] Neuenschwander, D.E. (2011) Emmy Noether's Wonderful Theorem. The Johns Hopkins University Press, Baltimore.

[51] Lobovikov, V.O. (2021) Applying Logic and Discrete Mathematics to Philosophy of Nature: Precise Defining “Time”, "Matter", and "Order” in Metaphysics and Thermodynamics. Open Journal of Philosophy, 11, 104-124. https://doi.org/10.4236/ojpp.2021.111009

[52] Lobovikov, V.O. (2021) A Formal Deductive Inference of the Law of Inertia in a Logically Formalized Axiomatic Epistemology System Sigma from the Assumption of Knowledge A-Priori-Ness. Journal of Applied Mathematics and Physics, 9, 441-467. 
https://doi.org/10.4236/jamp.2021.93031

[53] Lobovikov, V.O. (2014) Algebra of Morality and Formal Ethics. In: Bronk, K., Ed., Looking Back to See the Future. Reflections on Sins and Virtues, Interdisciplinary Press, Oxford, 17-41.

[54] Feynman, R.P. (1992) The Character of Physical Law. Penguin Books Ltd., London.

[55] Guthrie, W.K.C. (1965) A History of Greek Philosophy, II: The Presocratic Tradition from Parmenides to Democritus. Cambridge University Press, Cambridge.

[56] Lobovikov, V.O. (2005) "Prolegomena" by I. Kant and Impossibility of Perpetuum Mobile as a Principle of Pure A-Priori Knowledge of Nature (A Discrete Mathematical Model of Metaphysics in General and of Metaphysics of Nature Especially) ["Prolegomeny" I. Kanta i nevozmozhnost' vechnogo dvigatelya kak apriornyj princip chistogo estestvoznaniya (Diskretnaya matematicheskaya model' metafiziki voobshche i metafiziki prirody v osobennosti]. Scientific Yearbook of the Institute of Philosophy and Law of the Ural Branch of Russian Academy of Sciences [Nauchnyj ezhegodnik Instituta filosofii i prava Ural'skogo otdeleniya Rossijskoj akademii nauk], 5, 82-115. (In Russian)

[57] Lobovikov, V.O. (2020) Knowledge Logic and Algebra of Formal Axiology: A Formal Axiomatic Epistemology Theory Sigma Used for Precise Defining the Exotic Condition under Which Hume-and-Moore Doctrine of Logically Unbridgeable Gap between Statements of Being and Statements of Value Is Falsified. Antinomies, 20, 7-23.

[58] Lobovikov, V.O. (2016) An Axiomatization of Philosophical Epistemology (A Conceptual Synthesis of the Rationalism by Leibniz and the Empiricism by Locke, Hume, Moore). Journal of Tomsk State University. Series. Philosophy, Sociology, Political Studies, 36, 69-78. https://doi.org/10.17223/1998863X/36/7

[59] Lobovikov, V.O. (2018) Evolutionary Epistemology and Non-Normal Modal Logic of Knowledge. Journal of Tomsk State University. Series. Philosophy, Sociology, Political Studies, 41, 5-14. https://doi.org/10.17223/1998863X/41/1

[60] Lobovikov, V.O. (2018) Proofs of Logic Consistency of a Formal Axiomatic Epistemology Theory $\Xi$, and Demonstrations of Improvability of the Formulae $(\mathrm{Kq} \rightarrow \mathrm{q})$ and $(\square \mathrm{q} \rightarrow \mathrm{q})$ in It. Journal of Applied Mathematics and Computation, 2, 483-495. https://doi.org/10.26855/jamc.2018.10.004

[61] Ivin, A.A. (1970) Foundations of Evaluation Logic [Osnovanija Logiki Ocenok]. Izdatel'stvo Moskovskogo Universiteta, Moscow. (In Russian)

[62] Ivin, A.A. (1973) Logic of Norms [Logika Norm]. Izdatel'stvo Moskovskogo Universiteta, Moscow. (In Russian)

[63] Kant, I. (1994) The Critique of Pure Reason. Fundamental Principles of the Metaphysics of Morals. The Critique of Practical Reason. Preface and Introduction to the Metaphysical Elements of Ethics. General Introduction to the Metaphysics of Morals. The Science of Right. The Critique of Judgment. In: Adler, M.J., Ed., Great Books of the Western World, Vol. 39, Kant, Encyclopedia Britannica, Inc., Chicago; London, 1-613.

[64] Kant, I. (1996) Prolegomena to Any Future Metaphysics: in Focus. Routledge, London, New York. https://doi.org/10.1017/CBO9781139164061

[65] Kant, I. (2004) Metaphysical Foundations of Natural Science. Cambridge University Press, Cambridge, New York. https://doi.org/10.1017/CBO9780511809613

[66] Massimi, M. (2014) Kant and the Lawfulness of Nature. Kant-Studien, 105, 469-470. https://doi.org/10.1515/kant-2014-0021 
[67] Massimi, M. (2014) Prescribing Laws to Nature. Part I. Newton, the Pre-Critical Kant, and Three Problems about the Lawfulness of Nature. Kant-Studien, 105, 491-508. https://doi.org/10.1515/kant-2014-0023

[68] Massimi, M. and Breitenbach, A. (2017) Kant and the Laws of Nature. Cambridge University Press, New York. https://doi.org/10.1017/9781316389645

[69] Pollok, K. (2014) The Understanding Prescribes Laws to Nature: Spontaneity, Legislation, and Kant's Transcendental Hylomorphism. Kant-Studien, 105, 509-530. https://doi.org/10.1515/kant-2014-0024

[70] Watkins, E. (2014) What Is, for Kant, a Law of Nature? Kant-Studien, 105, 471-490. https://doi.org/10.1515/kant-2014-0022

[71] Hume, D. (1874) A Treatise of Human Nature being an Attempt to Introduce the Experimental Method of Reasoning into Moral Subjects. In: Green, T.H. and Grose, T.H., Eds., The Philosophical Works of David Hume in Four Volumes II, Longmans, Green, and Co., London, 1-374.

[72] Hume, D. (1994) An Enquiry Concerning Human Understanding. In: Adler, M.J., Ed., Great Books of the Western World, Vol. 33, Encyclopedia Britannica, Inc., Chicago, 451-509.

[73] Moore, G.E. (2004) Principia Ethica. Dover Publications, Mineola.

[74] von Wright, G.H. (1963) Norm and Action. A Logical Inquiry. Routledge \& Kegan Paul, London.

[75] von Wright, G.H. (1963) An Essay on Deontic Logic and the General Theory of Action. North Holland, Amsterdam.

[76] von Wright, G.H. (1983) Philosophical Papers. V. I: Practical Reason. Basil Blackwell, Oxford. https://doi.org/10.7591/9781501717314 